Research Article

\title{
Structural Optimization of Ship Lock Heads during Construction Period considering Concrete Creep
}

\author{
Chao Su (i) and Jiawei Bai (iD \\ College of Water Conservancy and Hydropower Engineering, Hohai University, Nanjing 210098, China \\ Correspondence should be addressed to Jiawei Bai; hhbjw.edu.com@hhu.edu.cn
}

Received 1 July 2020; Revised 29 July 2020; Accepted 31 July 2020; Published 26 August 2020

Academic Editor: Andras Szekrenyes

Copyright (C) 2020 Chao Su and Jiawei Bai. This is an open access article distributed under the Creative Commons Attribution License, which permits unrestricted use, distribution, and reproduction in any medium, provided the original work is properly cited.

\begin{abstract}
Traditional structural optimization is mainly based on the assumption that the materials are elastic, which cannot represent real stress fields in structures. In this study, the genetic algorithm, big bang-big crunch algorithm, and hybrid big bang-big crunch algorithm were employed to optimize the design factors of ship lock heads during concrete construction. The optimization goal was to determine the minimum volume of concrete. The factors considered included the hydration heat, the early-stage creep, and the transient deformation under external loads. In the finite element analysis, three types of boundary conditions were considered. The whole construction process was simulated, and the maximum tensile and compressive stresses, the stability, and the overturning of the lock head were examined. Based on the finite element analysis, to reduce the consumption of memory, a set of implicit recursive equations were used to calculate the thermal creep stress. Thirty-four design variables were distinguished for optimization. A case study on the optimization of a ship lock head was used to demonstrate the optimization process. The optimization results showed that the hybrid big bang-big crunch algorithm was more effective, and some conclusions were derived.
\end{abstract}

\section{Introduction}

Ship locks are one of the most critical massive concrete structures used in inland waterways. Surmounting differences in the water level is the primary role of ship locks [1]. The lock head is a complex part of a lock. The finite element method (FEM) has been used to optimize lock heads [2]. Obtaining reliable safety with the best possible minimum volume of concrete is the optimization objective of this study. Due to the time-dependent properties of mass concrete structures [3], temperature and creep should also be studied. The hydration temperature effects are strong during the construction period [4]. They often cause the mass concrete temperature to rise by $40-70^{\circ} \mathrm{C}$, and thermal stressinduced cracking can be generated [5]. Thermal stress-induced cracking poses a significant threat to mass concrete durability [6]. In addition, creep can relax the thermal stress of early-age concrete [7]. Therefore, to understand the influence of the optimization on the structural properties during the construction period, structural optimization should consider the evolution of the temperature field and creep.

Genetic algorithms (GAs) are intelligent search algorithms. They are widely used due to their functional properties in different engineering application areas, such as structural optimization [8], automated management [9], safety evaluation [10], sensitivity analysis [11], and back analysis [12]. For optimization problems, GAs can typically generate high-quality solutions with an adaptive search mechanism. The three main characteristics of GAs in structural optimization problems are as follows [13]: (1) they exhibit excellent searchability for the global optimal solution, (2) they discretize the design variables, and (3) the constraints are modifiable. Erol and Eksin [14] developed the big bang-big crunch (BB-BC) algorithm, which is a more robust method than GAs [15]. This algorithm converges quickly [16]. Kaveh and Talatahari [17] proposed the hybrid big bang-big crunch (HBB-BC) algorithm to improve the 
search capability of the BB-BC method. The HBB-BC algorithm integrates the particle swarm optimization (PSO) and BB-BC algorithms [18].

Mass concrete structures have long construction periods and complicated construction sequences, such as concreting, formwork, and dismantling formwork. Rita et al. [19] optimized the thick concrete foundation of a building to minimize the construction cost. They analysed the temperature and stress fields of the structure during the construction period, and the results guaranteed that the structure would not generate thermal cracks. Fairbairn et al. [20] optimized a small hydropower plant dam to minimize the construction cost. They used a coupled thermal-chemical-mechanical model to calculate the transient hydration, temperature, and stress fields during the construction period. The results indicated that the developed procedure is suitable for the design of dams. However, few optimization studies have simulated the real temperature fields and stress states of ship lock heads during the construction period.

The study of the temperature field of mass concrete structures is not a new issue. In the 1920s, the Schmidt method was developed [21]. This method is a numerical method for predicting temperatures throughout mass concrete elements, and it is convenient for manual calculations. It is a simplified finite difference formulation. However, it is more suitable for heat conduction problems with rectangular shapes. Due to the advances in computer science, Wilson et al. [22] applied the finite element method to the solution of the transient heat conduction problem. This method is suitable for complex solids with arbitrary shapes. It also accounts for heat flux and temperature boundary conditions. Wilson et al. [23] subsequently presented techniques for solving large and complex three-dimensional heat conduction problems. On this basis, a series of research articles were published [4, 24]. Yang et al. [25] discovered that a structure's geometric dimensions can affect the temperature distribution of the concrete. Structural optimization will change the sizes of the mass concrete structures. The rate and amount of temperature change are two crucial factors for evaluating the temperature field [26]. However, few studies have analysed the effects of structural optimization on the temperature fields of mass concrete structures.

The creep deformation is of utmost importance in early-age concrete. Therefore, to truly calculate the stress field of mass concrete structures, a creep model must be included in mechanical analyses [27]. Creep is a viscoelastic property of concrete [28]. In recent decades, several creep models have been developed, such as the B3 model [29], the M4 model [30], and the ACI 209R-92 model [31]. Bažant and $\mathrm{Xi}$ [32] found that the Kelvin chain was accurate enough to describe any linear viscoelastic behaviour, and its parameters were easily determined from creep tests. Creep is influenced by stress history [33]. Consequently, the entire history must be stored during the calculation process, which limits the application of creep models in mass concrete structures. Bažant and Xi [32] converted creep compliance functions to a Dirichlet series. Zhu [34] derived a set of implicit recursive equations without requiring the stress history to be stored. This method was used to calculate the thermal creep stress. However, most studies on structural optimization assumed that the materials were elastic [35]. Few optimization studies have calculated the stress fields of mass concrete structures using creep models and analysed the effects of structural optimization on the thermal creep stress.

This study aimed to determine the optimal shape of ship lock heads and analyse the influence of structural optimization on the temperature and stress fields during the construction period. The GA, BB-BC, and HBB-BC algorithms were used to solve the optimization problem of a ship lock head, and corresponding optimization procedures were proposed. In the optimization process, the optimization objective was to determine the minimum volume of concrete. The set of design variables contained 34 parameters. The remaining sections of this paper are organized as follows. In Section 2, the theoretical formulations of the temperature field and the thermal creep stress are described. In Section 3, the optimization problem of a ship lock head is established. In Section 4, the key points for applying the GA, BB-BC, and HBB-BC algorithms to optimize a ship lock head are established. In Section 5, a complete example with analysis is provided. Finally, the valuable conclusions drawn from the study are summarized in Section 6.

\section{Theoretical Formulations}

2.1. Calculation Principle of Temperature Field. According to Fourier's law of heat conduction and the energy conservation principle, the governing equation of a three-dimensional transient temperature field is expressed as follows [36]:

$$
\rho c \frac{\partial T}{\partial t}=k\left(\frac{\partial^{2} T}{\partial x^{2}}+\frac{\partial^{2} T}{\partial y^{2}}+\frac{\partial^{2} T}{\partial z^{2}}\right)+\frac{\partial Q}{\partial t},
$$

where $\rho$ is the material density, $c$ is the specific heat of the materials, $T$ is the concrete temperature, $k$ is the thermal conductivity coefficients, and $Q$ is the heat of hydration introduced per unit volume. The initial condition is as follows [37]:

$$
T=T_{0}(x, y, z), \quad \text { when } t=0 .
$$

There are three types of boundary conditions for concrete structures, which are denoted as $S_{1}, S_{2}$, and $S_{3}$. The boundary conditions are expressed as follows [37].

On boundary $S_{1}$, the function of temperature $(T)$ is known:

$$
T(t)=f_{1}(t), \quad \text { on boundary } S_{1} .
$$

On boundary $S_{2}$, the thermal flux density is a function of time:

$$
-k \frac{\partial T}{\partial n}=q(t), \quad \text { on boundary } S_{2} .
$$

On boundary $S_{3}$, a convective-type condition is applied: 


$$
-k \frac{\partial T}{\partial n}=\beta\left(T-T_{a}\right), \quad \text { on boundary } S_{3} .
$$

In these boundary conditions, $n$ represents the external normal direction to the boundary, $\beta$ represents the surface exothermic coefficient, and $T_{a}$ is the atmospheric temperature.

The finite element method (FEM) can be used to solve the above problem using the following equation [38]:

$$
[C]^{e}\left\{\frac{\partial T}{\partial t}\right\}+\left[K_{t}\right]^{e}\{T\}-\left\{R_{t}\right\}^{e}=0,
$$

where $[C]^{e}$ represents the capacitance matrix, $\left[K_{t}\right]^{e}$ represents the heat stiffness matrix, and $\left\{R_{t}\right\}^{e}$ represents the total load heat vector.

Using the finite difference approximation, equation (6) was solved in the time domain numerically. After assembling the stiffness matrices, the solution can be obtained as the following equation [39]:

$$
\begin{aligned}
\left([C]+\theta \Delta t\left[K_{t}\right]\right)\{T\}_{b}= & \left([C]+(1-\theta) \Delta t\left[K_{t}\right]\right)\{T\}_{a} \\
& +\Delta t\left((1-\theta)\left\{R_{t}\right\}_{a}+\theta\left\{R_{t}\right\}_{b}\right),
\end{aligned}
$$

where $\{T\}_{b}$ and $\left\{R_{t}\right\}_{b}$ represent $\{T\}$ and $\left\{R_{t}\right\}$ at time $(b)$, respectively, and $\{T\}_{a}$ and $\left\{R_{t}\right\}_{a}$ represent $\{T\}$ and $\left\{R_{t}\right\}$ at time (a), respectively. According to the Galerkin method, $\theta$ equals $2 / 3$. Equation (7) can be written in the following general form [38]:

$$
\begin{aligned}
{\left[A_{G}^{*}\right]\{\Delta T\} } & =\left\{R_{G}^{*}\right\}, \\
{\left[A_{G}^{*}\right] } & =\frac{1}{\Delta t}[C]+\frac{2}{3}\left[K_{t}\right], \\
\left\{R_{G}^{*}\right\} & =\frac{1}{2}\left(\left\{R_{t}\right\}_{a}+2\left\{R_{t}\right\}_{b}-3\left[K_{t}\right]\{T\}_{a}\right),
\end{aligned}
$$

where $\{\Delta T\}$ is the temperature change with respect to time $\Delta t$ at nodal points. The equation for evaluating the temperatures at the new time point is as follows [38]:

$$
\{T\}_{b}=\{T\}_{a}+\frac{2}{3}\{\Delta T\} .
$$

\subsection{Calculation Principle of Thermal Creep Stress}

2.2.1. Equations of Creep Strain Increment. According to the ACI 209R-92 model [31], the compliance function is given as follows:

$$
J(t, \tau)=\frac{1}{E(\tau)}+C(t, \tau)
$$

For mass concrete structures, the creep compliance function can be expressed as follows [34]:

$$
C(t, \tau)=\sum_{i=1}^{m} \psi_{i}(\tau)\left\{1-\exp \left[-r_{i}(t-\tau)\right]\right\}
$$

In addition,

$$
\begin{aligned}
& E(\tau)=E_{0}\left[1-\exp \left(\alpha \tau^{\lambda}\right)\right], \\
& \psi_{i}(\tau)=A_{i}+B_{i} \tau^{C_{i}},
\end{aligned}
$$

where $t$ represents the calculated age, $\tau$ represents the loading age, $E(\tau)$ represents the transient elastic modulus, $E_{0}$ represents the ultimate elastic modulus, $m$ equals the number of Kelvin elements, and $r_{i}, \alpha, \lambda, A_{i}, B_{i}$, and $C_{i}$ are the experimental fitting parameters [4].

In a typical time increment $\Delta \tau_{n}\left(\tau_{n-1} \longrightarrow \tau_{n}\right)$, the formulas of the creep strain increment $\left\{\Delta \varepsilon_{n}^{c}\right\}$ and the stress increment $\left\{\Delta \sigma_{n}\right\}$ in $3 \mathrm{D}$ are expressed as the following equation [34]:

$$
\left\{\Delta \varepsilon_{n}^{c}\right\}=\left[\eta_{n}\right]+C\left(\tau_{n}, \bar{\tau}_{n}\right)[Q]\left\{\Delta \sigma_{n}\right\},
$$

where

$$
\begin{aligned}
\left\{\eta_{n}\right\} & =\sum_{i=1}^{m}\left[1-\exp \left(-r_{i} \Delta \tau_{n}\right)\right]\left\{\omega_{i n}\right\}, \\
\left\{\omega_{i n}\right\} & =\left\{\omega_{i n-1}\right\} \exp \left(-r_{i} \Delta \tau_{n-1}\right)+[Q] \psi_{i}\left(\bar{\tau}_{n-1}\right)\left\{\Delta \sigma_{n-1}\right\} \\
\left\{\omega_{i 1}\right\} & =[Q] \psi_{i}\left(\tau_{0}\right)\left\{\Delta \sigma_{0}\right\}, \\
{[Q] } & =\left[\begin{array}{cccccc}
1 & -\mu & -\mu & 0 & 0 & 0 \\
-\mu & 1 & -\mu & 0 & 0 & 0 \\
-\mu & -\mu & 1 & 0 & 0 & 0 \\
0 & 0 & 0 & 2(1+\mu) & 0 & 0 \\
0 & 0 & 0 & 0 & 2(1+\mu) & 0 \\
0 & 0 & 0 & 0 & 0 & 2(1+\mu)
\end{array}\right] .
\end{aligned}
$$

In these equations, $\bar{\tau}_{n}=\left(\tau_{n-1}+\tau_{n}\right) / 2$, [Q] represents Poisson's ratio matrix, and $\mu$ represents Poisson's ratio [40].

2.2.2. Equations of Thermal Creep Stress. In a time increment, the total strain increment is given in the following equation [7]:

$$
\left\{\Delta \varepsilon_{n}\right\}=\left\{\Delta \varepsilon_{n}^{e}\right\}+\left\{\Delta \varepsilon_{n}^{T}\right\}+\left\{\Delta \varepsilon_{n}^{c}\right\}
$$

where $\left\{\Delta \varepsilon_{n}\right\}$ is the total strain increment, $\left\{\Delta \varepsilon_{n}^{e}\right\}$ is the elastic strain increment, and $\left\{\Delta \varepsilon_{n}^{T}\right\}$ is the thermal strain increment.

The thermal strain increment is calculated by the following equation:

$$
\left\{\Delta \varepsilon_{n}^{T}\right\}=\zeta\{\Delta T\}\left[\begin{array}{llllll}
1 & 1 & 1 & 0 & 0 & 0
\end{array}\right]^{T},
$$

where $\zeta$ is the linear expansion coefficient.

Based on equations (14)-(17), $\left\{\eta_{n}\right\}$ is not related to the current stress increment. Therefore, the formulas of the stress and strain increment can be obtained as follows [4]:

$$
\left\{\Delta \sigma_{n}\right\}=\left[\bar{D}_{n}\right]\left(\left\{\Delta \varepsilon_{n}\right\}-\left\{\eta_{n}\right\}-\left\{\Delta \varepsilon_{n}^{T}\right\}\right),
$$

where

$$
\left[\bar{D}_{n}\right]=\frac{1}{J(t, \tau)}[Q]^{-1}=\frac{E\left(\bar{\tau}_{n}\right)}{1+C\left(\tau_{n}, \bar{\tau}_{n}\right) E\left(\bar{\tau}_{n}\right)}[Q]^{-1},
$$


in which $\left[\bar{D}_{n}\right]$ is the viscoelastic modulus.

\section{Optimization Problem of Ship Lock Head}

3.1. Geometric and Mesh Models of Ship Lock Head. The structural optimization of ship lock heads involves determining the size of the lock heads. Therefore, a geometric model of a ship lock head should be established. Along the direction of the water flow, the lock head is left-right symmetric, and thus, half of the structure was selected for parametric modelling. Figure 1(a) shows a typical 3D lock head model, and Figure 1(b) also contains the bedrock and three layers of backfilled gravel.

As shown in Figure 2, the design parameters of the bottom plate are defined as $X_{b i}(i=1-10), Y_{b i}(i=1-10)$, and $Z_{b i}(i=1-3)$ in three dimensions. The coordinate origin is the point $O$. Figure 3 shows a typical section of the second-stage concrete. The design parameters include the following: $R_{s i}$ $(i=1-2)$ are the arc radii, $\theta_{s i}(i=1-7)$ are the flip angles, and $S_{s i}(i=1-5)$ are the oblique length parameters. Figure 4 shows the design of a typical section of the corridor layer. Combining the design of the bedrock and backfilled gravel, the design of the overall geometric model (as shown in Figure 1(b)) requires 170 parameters.

In the FEM simulation, manually meshing is a timeconsuming task. Therefore, an automated gridding program written in Python was applied in ABAQUS. The workflow of this program was as follows. Using design parameters, the three structures (as shown in Figure 1(b)) were divided into regular bulks. Meshes of the regular bulks were generated by calling the meshing tool of ABAQUS. During this process, each bulk was called by the corresponding design parameters.

3.2. Design Variables. As shown in Figure 5, the design variables cover 34 parameters of the corridor layer and the empty-box layer, which are denoted as $x_{1}, \ldots, x_{12}, y_{1}, \ldots, y_{7}$, and $z_{1}, \ldots, z_{15}$ in the $x, y$, and $z$ directions, respectively. The coordinate origin of the parametric design is the point $O$.

3.3. Design Loads. The ship lock head is affected by the following loads during the construction period.

3.3.1. Self-Weight. The self-weight of a ship lock head includes the weight of the concrete and structures fixed to the lock head, such as the lock gate.

3.3.2. Gravel Backfill Pressure. As shown in Figure 1(a), the ship lock head is a gravity-type structure. Therefore, the gravel backfill pressure can be calculated based on Rankine's theory [41]:

$$
\begin{aligned}
& E_{a}=\left(\gamma_{z} h_{z}+q_{z}\right) K_{a}-2 c_{a} \sqrt{K_{a}}, \\
& K_{a}=\tan ^{2}\left(45^{\circ}-\frac{\varphi_{z}}{2}\right),
\end{aligned}
$$

where $E_{a}$ is the horizontal unit active backfill pressure, $\gamma_{z}$ is the unit weight of the backfill, $h_{z}$ is the thickness of the backfill, $q_{z}$ is the vertical surcharge pressure on the backfill surface, $c_{a}$ is the cohesion, $K_{a}$ is the active pressure coefficient of the backfill, and $K_{a}$ is the internal friction angle of the backfill.

3.3.3. Design Live Load. In this study, the design live load was assumed to be $5 \mathrm{kPa}$, as specified in a previous publication [41].

3.3.4. Temperature Load. The heat of hydration is time dependent and can be expressed by the following equation [34]:

$$
Q(\tau)=Q_{\infty}\left[1-\exp \left(-A_{\infty} \tau^{B_{\infty}}\right)\right]
$$

where $Q(\tau)$ is the accumulated heat at time $\tau, Q_{\infty}$ is the final value of the cement hydration heat, and $A_{\infty}$ and $B_{\infty}$ are the experimental fitting parameters.

3.4. Constraints. There are three types of constraints for optimizing a ship lock head to meet the engineering safety requirements:

Geometric Constraints. To guarantee that the finite element program can automatically generate FEM meshes during optimization, design variables, as shown in Section 3.2, must be provided with value ranges.

Stress Constraints. According to the Code for Design of Hydraulic Structures of Ship Locks, the principal stresses should satisfy $\sigma_{1} \leq\left[\sigma_{1}\right]$ and $\sigma_{3} \leq\left[\sigma_{3}\right]$, where $\sigma_{1}$ is the first principal stress, $\sigma_{3}$ is the third principal stress, $\left[\sigma_{1}\right]$ is the allowable value of the principal tensile stress, and $\left[\sigma_{3}\right]$ is the allowable value of the principal compressive stress.

Stability Constraints. During the construction period, stability constraints contain antisliding stability and antioverturning stability. The safety factor of the antisliding stability constraint is as follows [41]:

$$
K_{s}=\frac{f \sum V}{\sum H} \geq\left[K_{s}\right],
$$

where $K_{s}$ represents the safety factor of the antisliding stability, $f$ represents the friction coefficient, $\sum V$ represents the total sum of loads along the normal direction of the sliding surface, $\sum H$ represents the total sum of loads along the tangent direction of the sliding surface, and $\left[K_{s}\right]$ represents the allowable value of the safety factor. The safety factor of the antioverturning stability constraint is as follows [41]:

$$
K_{m}=\frac{M_{R}}{M_{m}} \geq\left[K_{m}\right],
$$



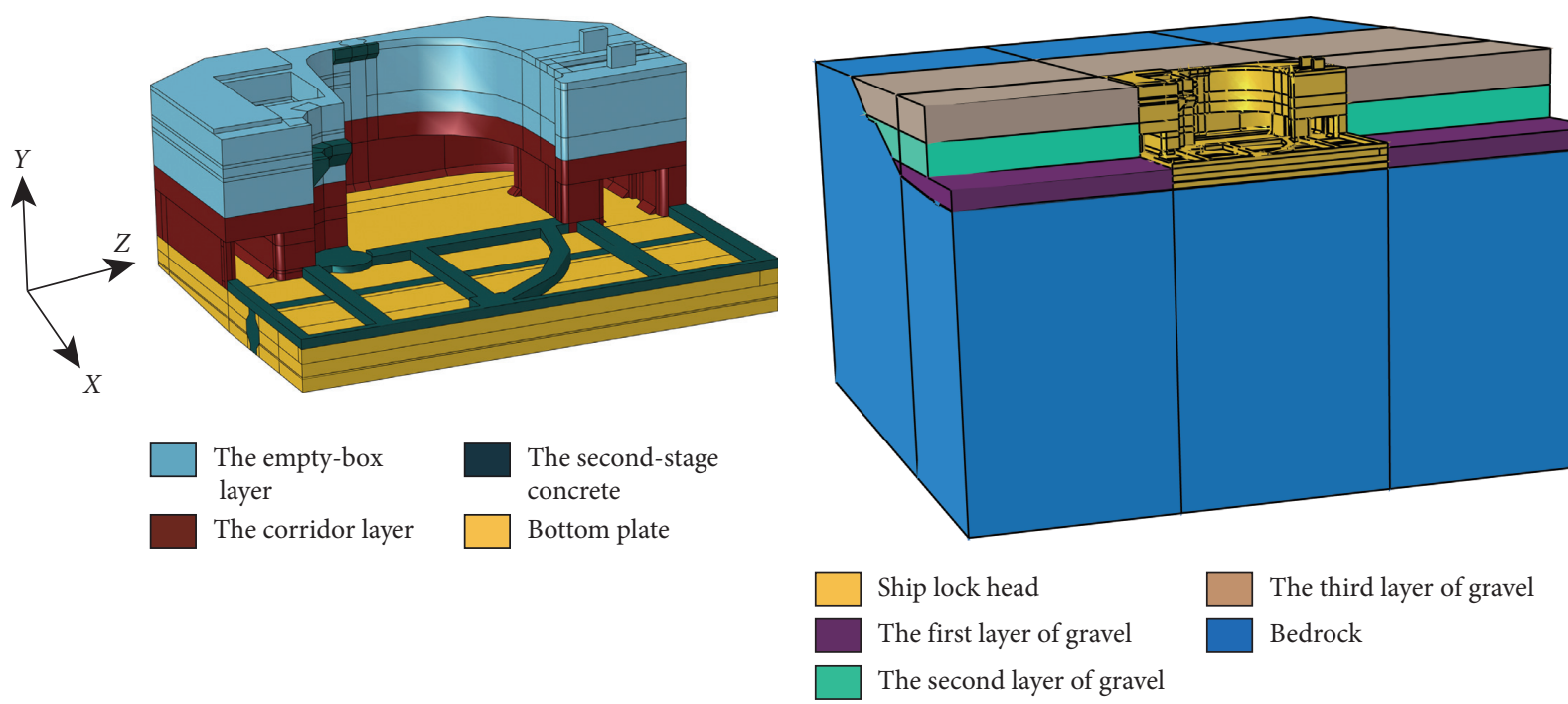

(a)

(b)

Figure 1: Geometric models of (a) the ship lock head and (b) the ship lock head-bedrock-backfilled gravel system.

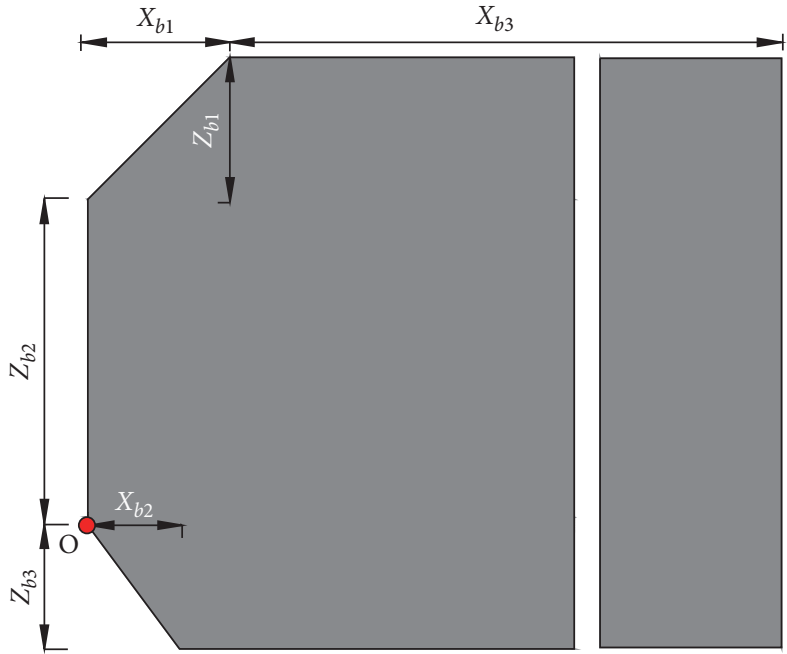

(a)

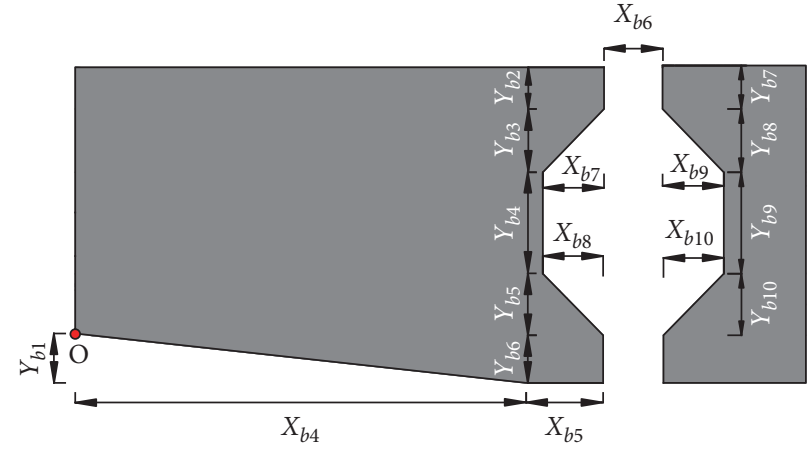

(b)

Figure 2: Design of the bottom plate. (a) Horizontal plan of the bottom plate. (b) Elevation view of the bottom plate.

where $K_{m}$ represents the safety factor of the antioverturning stability, $M_{R}$ represents the total sum of steady moments on the cross section of the calculation, $M_{m}$ represents the total sum of overturning moments on the cross section of the calculation, and $\left[K_{m}\right]$ represents the allowable value of the safety factor.

3.5. Objective Function. In this study, the goal was to minimize the volume of concrete such that the stress and stability requirements were satisfied. The following equation defines the objective function $m(x)$ :

$$
m(x)=1-\frac{\left[v_{0}-v(x)\right]}{v_{0}},
$$

where $x=\left(x_{1}, \ldots, x_{12}, y_{1}, \ldots, y_{7}, z_{1}, \ldots, z_{15}\right)$ represents the updating parameters, $v_{0}$ represents the volume of the initial ship lock head, and $v(x)$ represents the volume of the optimum lock head. The optimization problem proposed in this study can be summarized as a problem of finding the objective function to minimize. If a design does not satisfy the constraints (as shown in Section 3.4), the objective function of the design must be set to a very large number as a penalty to the optimization process so as to greatly reduce the impact of this scheme on the optimization search and improve the optimization efficiency. A penalized objective function is applied, which is defined as follows:

$$
m(x)=\gamma,
$$




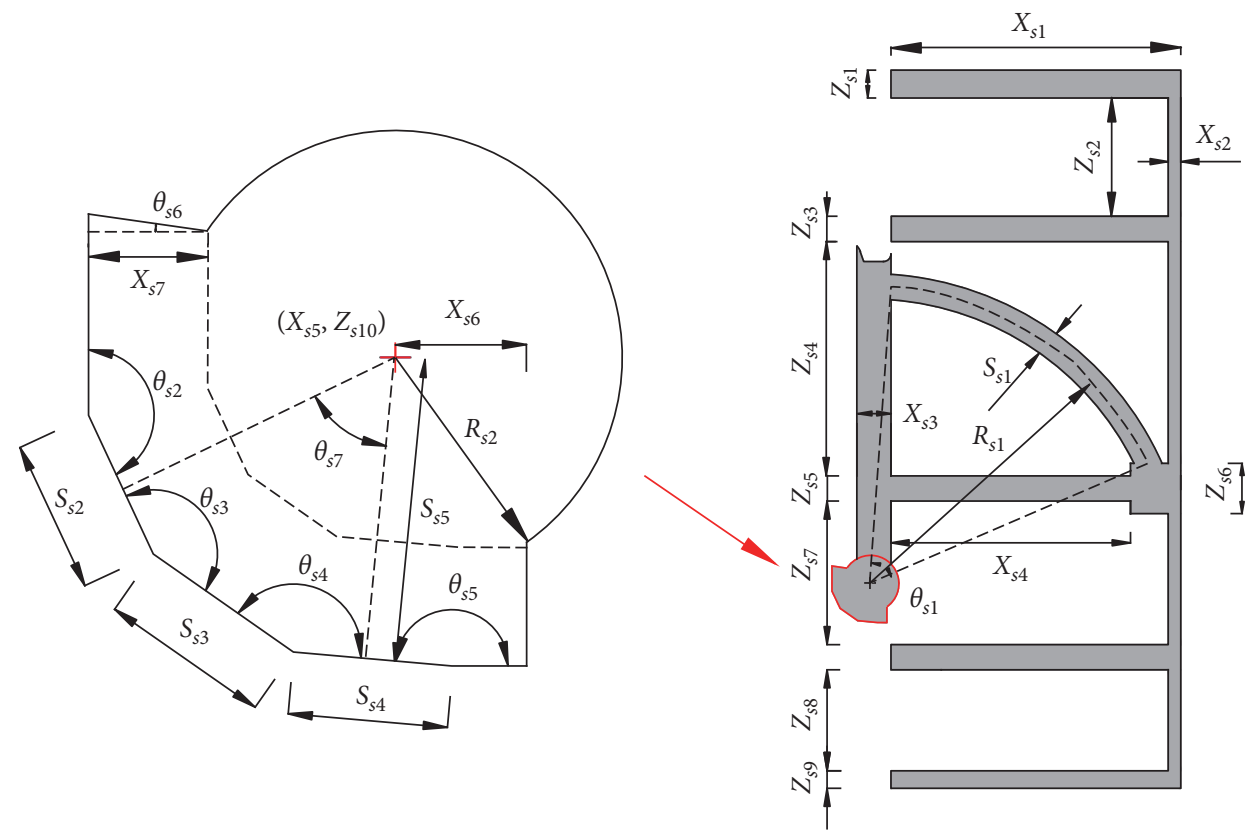

FIgURe 3: Typical section of the second-stage concrete.
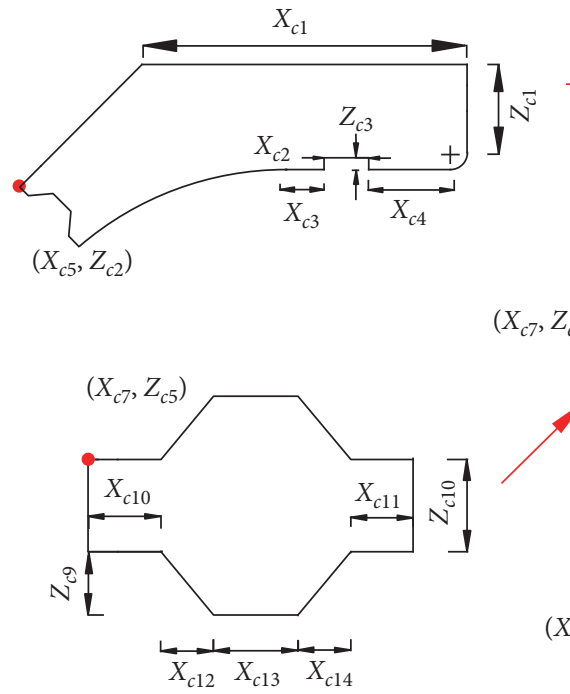

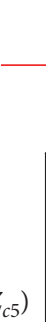

$\left(X_{c 5}, Z_{c 2}\right)$
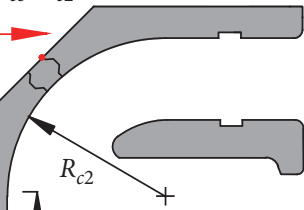

$\left(X_{c 7}, Z_{c 5}\right)$
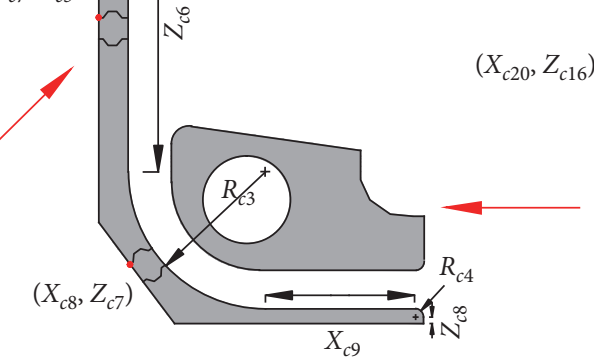

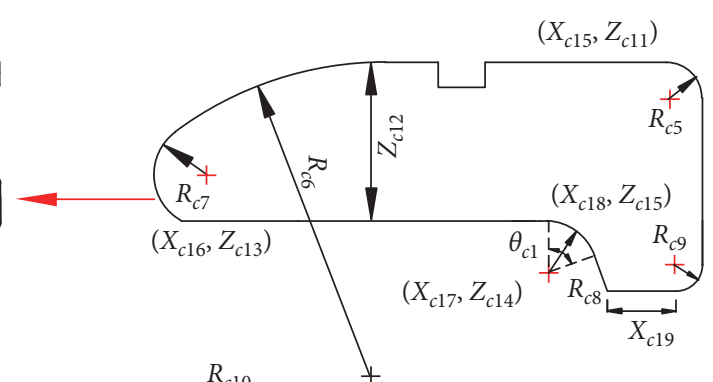

Figure 4: Typical section of the corridor layer.

where $\gamma=99,999$ in this study.

\section{Concepts of Genetic Algorithm (GA), Big Bang-Big Crunch Algorithm (BB-BC), and Hybrid Big Bang-Big Crunch Algorithm (HBB-BC)}

\subsection{Concept of $G A$}

4.1.1. Basic Concept. GAs are heuristic algorithms [42] that simulate the theory of natural selection in evolution proposed by Charles Darwin. A GA is an evolutionary optimization method [43]. It starts by converting initial solutions (design variables) to a population of chromosomes. The initial solutions are selected randomly in the ranges of values for the design variables. Selection, crossover, and mutation operators are the three basic genetic operators. These operators improve initial parent solutions to generate better solutions. Briefly, in the selection stage, the probability of each chromosome being selected is determined by calculating the objective function (as shown in Section 3.5). The crossover and mutation operations are then applied to selected chromosomes to generate a better offspring group. Finally, the optimization procedure is terminated by reaching the stopping criterion.

In this study, each chromosome represents a set of solutions for the design variables. The number of design variables is expressed as parameter $N$, and each design variable is 

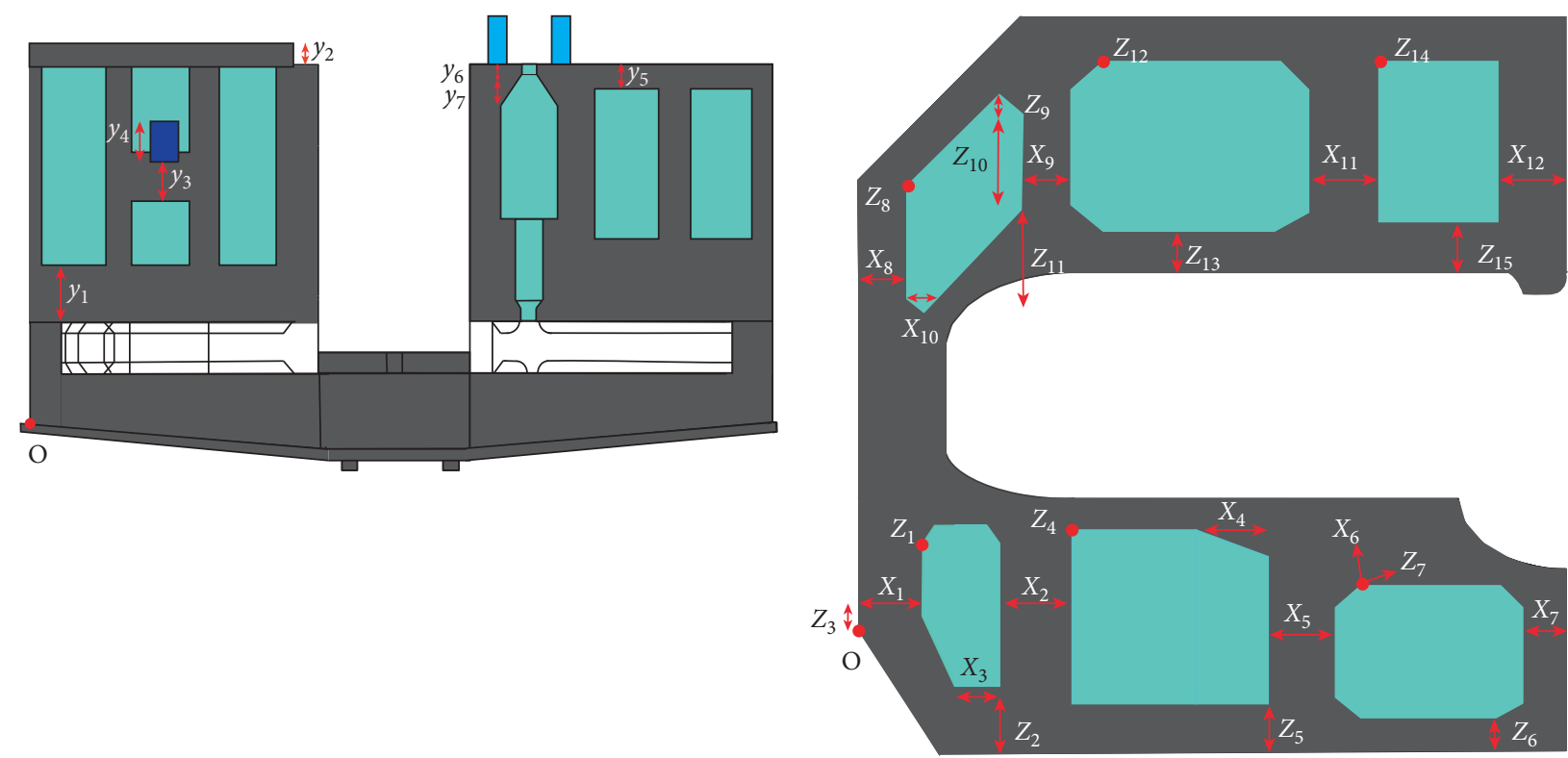

(a)

(b)

FIgURE 5: Design variables (a) in the $y$ direction and (b) in the $x$ and $z$ directions.

represented by a gene chain composed of four genes. Therefore, the total number of genes is $4 N$. A chromosome with three design variables is displayed in Figure 6(a).

4.1.2. Binary Encoding and Decoding. The value of each design variable is represented by a binary string in the optimization calculation. A modelling program was written in Python to complete the modelling work in ABAQUS. Because the design variables in parametric modelling must be real numbers, binary digits should be decoded into decimal numbers. They are interconverted using the following equation:

$$
\begin{aligned}
& X=X_{\min }+\frac{I}{2^{F}-1}\left(X_{\max }-X_{\min }\right), \\
& I=\sum_{j=0}^{N-1} a_{j} \cdot 2^{j} .
\end{aligned}
$$

Furthermore, the following constraint must be satisfied:

$$
\frac{X_{\max }-X_{\min }}{Y} \leq 2^{F},
$$

where $X$ is the value of each design variable, $X_{\min }$ is the minimum value of each design variable, $F$ is the number of chromosome genes used for each design variable, where in this study, $F=4, I$ is the decimal number of each design variable, $X_{\max }$ is the maximum value of each design variable, $a_{j}$ is the number of the $j$ th gene ( 0 or 1$)$, and $Y$ is the parameter increment of each design variable.

4.1.3. Population Initialization. The initial population is generated randomly after the binary coding. A two-dimensional array $W$ is used to represent the initial population. The chromosome of a set of design variables is a row object. Meanwhile, the population size is the number of corresponding columns. $W$ is expressed as follows:

$$
W=\left[\begin{array}{ccc}
W_{1}^{1} & \cdots & W_{1}^{p} \\
\vdots & \ddots & \vdots \\
W_{g}^{1} & \cdots & W_{g}^{p}
\end{array}\right]
$$

where $g$ is the population size and $p$ is the chromosome length, namely, the total number of genes in a chromosome. In this study, $p=4 N$.

\subsubsection{Genetic Operators}

Selection Operator. Selecting elite individuals to form new populations is the role of the selection operator. In this study, the selection operator is based on the roulette wheel selection method. As shown in Figure 6(b), the wheel represents the whole population from which the selection is made. The area of each individual is positively correlated with the probability of being selected. This selection probability can be calculated as follows:

$$
J_{i}=\frac{1 / F_{i}}{\sum_{i=1}^{N} 1 / F_{i}},
$$

where $J_{i}$ is the selection possibility of each individual and $F_{i}$ is the objective function value of each individual. Accordingly, the roulette wheel selection method consists of three steps. First, the selection possibility of each individual is calculated. Second, random numbers are generated and arranged from the smallest to the 

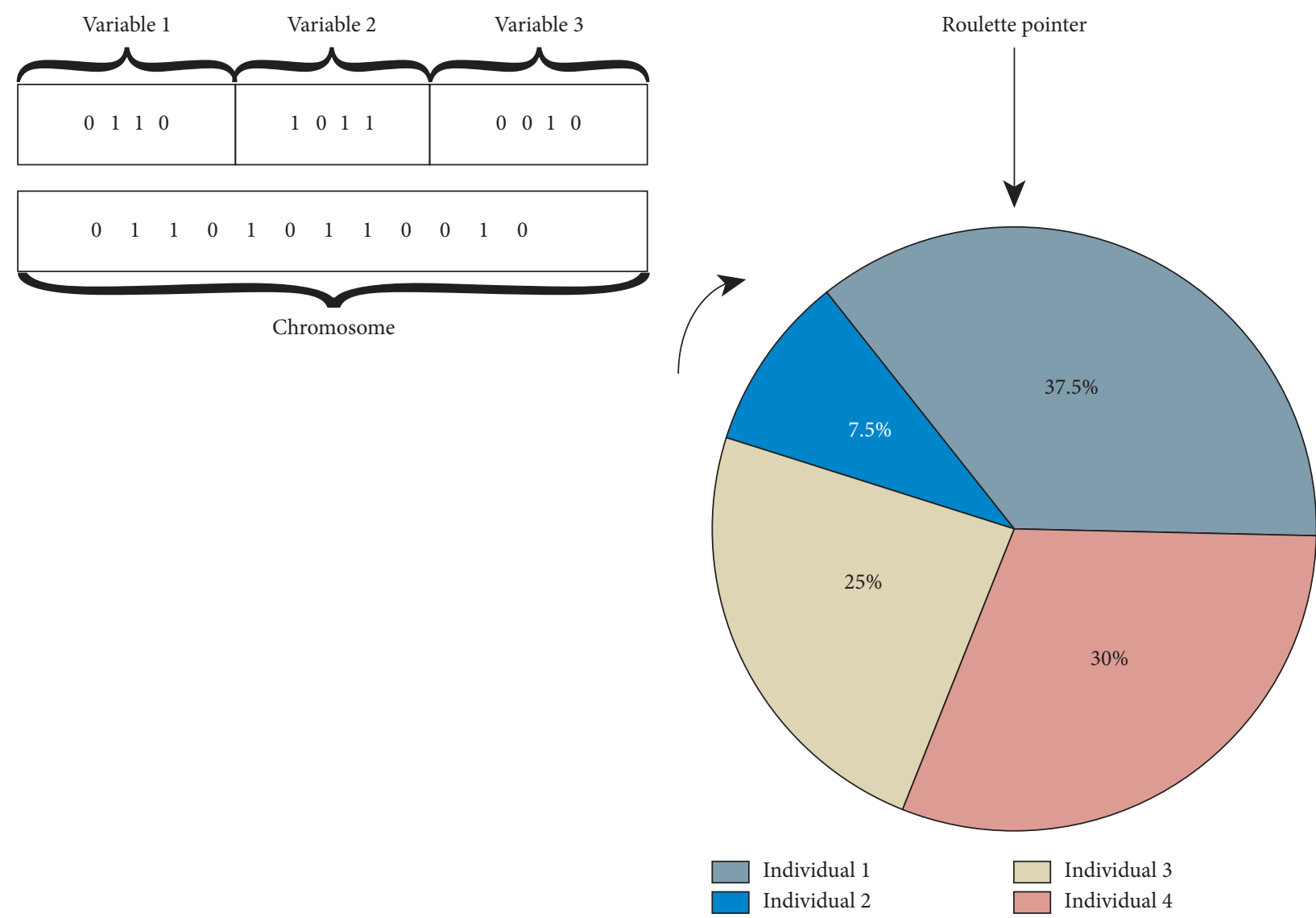

(a)
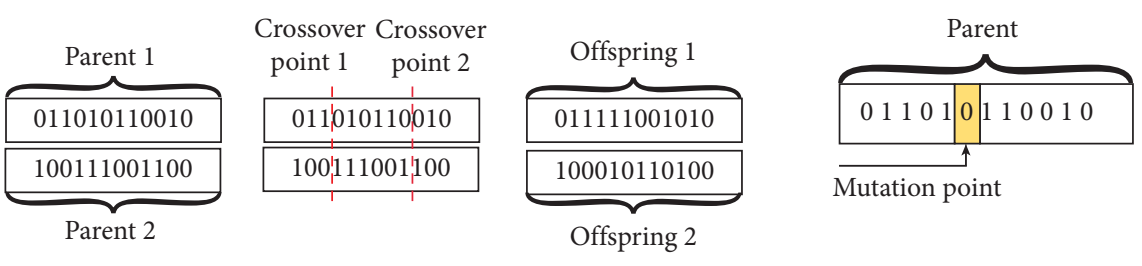

(b)

(c)

(d)

Figure 6: Schematic diagrams of the GA. (a) Chromosome representation of design variables. (b) Roulette wheel selection operator. (c) Two-point crossover operator. (d) Mutation operator.

largest. Finally, the individuals greater than the random numbers are kept by comparing each pair of random numbers and selection possibilities.

Crossover Operator. Generating two new chromosomes by exchanging genes between a pair of original chromosomes is the role of the crossover operator. The crossover probability $p_{c}$ is typically between 0.4 and 0.9 . In this study, a two-point crossover was adopted. As shown in Figure 6(c), genes of the two chromosomes between two randomly selected crossover points are exchanged, and two new chromosomes are generated. Mutation Operator. The mutation operator increases the population diversity. As shown in Figure 6(d), the bitflip mutation operator is adopted. A $0.8 \%$ mutation rate $p_{t}$ is used. In the chromosome, the mutation operator can change one gene by randomly producing a minor perturbation. A new chromosome is then generated.

4.2. Concept of $B B-B C$. The $\mathrm{BB}-\mathrm{BC}$ algorithm consists of two stages: A big bang step and a big crunch step [44]. In the first phase, some candidate solutions are randomly generated to cover the entire search space. In this step, each candidate's objective function value is calculated according to equation (26). In the second phase, the big crunch is a contraction operation that uses the objective function value and the current position of each design variable to calculate the "centre of mass." The term mass is actually the inverse of the 
objective function value. The centre of mass is calculated by the following equation [17]:

$$
X_{i}^{c(j, G)}=\frac{\sum_{j=1}^{g}\left(1 / F_{i}\right) X_{i}^{(j, G)}}{\sum_{j=1}^{g}\left(1 / F_{i}\right)}, \quad i=1,2, \ldots, N,
$$

where $x_{i}^{(j, G)}$ represents the $i^{\text {th }}$ design variable of candidate $j$ in iteration $G$.

After the big crunch step, the big bang step of the next iteration can be calculated using the following equations:

$$
\begin{gathered}
X_{\text {temp }}=X_{i}^{c(j, G)}+\frac{k_{j} n_{1}\left(X_{i \max }-X_{i \min }\right)}{G+1}, \quad i=1,2, \ldots, N, \\
X_{i}^{(j, G+1)}=X_{\text {temp }}, \quad i=1,2, \ldots, N ; \text { when } X_{i \min } \leq X_{\text {temp }} \leq X_{\text {imax }},
\end{gathered}
$$

$$
X_{i}^{(j, G+1)}=X_{i \max }, \quad i=1,2, \ldots, N ; \text { when } X_{\text {temp }} \geq X_{i \max }
$$

$$
X_{i}^{(j, G+1)}=X_{i \min }, \quad i=1,2, \ldots, N ; \text { when } X_{\text {temp }} \leq X_{i \min },
$$

where $X_{i}^{(j, G+1)}$ represents the new position of each design variable, $k_{j}$ represents a random number, $n_{1}$ represents a parameter that limits the size of the search space, $X_{i \max }$ represents the maximum value of each design variable, and $X_{i \text { in }}$ represents the minimum value of the $i^{\text {th }}$ design variable. The above two steps are repeated until the stopping criteria are met.

4.3. Concept of $H B B-B C$. Although the BB-BC algorithm has good performance in exploitation, it easily becomes trapped in local optimal solutions. The HBB-BC algorithm not only utilizes the "centre of mass" but also uses the global best solution $X_{i}^{g \text { best }(G)}$ and the best solution of the $G^{\text {th }}$ iteration $X_{i}^{\text {lbest }(j, G)}$ to generate a new group of candidates in the big bang step [17]. Equation (33) is replaced by the following equation [45]:

$$
\begin{aligned}
X_{\text {temp }}= & n_{2} X_{i}^{c(j, G)}+\left(1-n_{2}\right)\left(n_{3} X_{i}^{g \text { best }(G)}+\left(1-n_{3}\right) X_{i}^{l \text { best }(j, G)}\right) \\
& +\frac{k_{j} n_{1}\left(X_{i \max }-X_{i \min }\right)}{G+1}, \quad i=1,2, \ldots, N, j=1,2, \ldots, g
\end{aligned}
$$

where $n_{2}$ and $n_{3}$ are the parameters that adjust the influence of the global and local optimal solutions for the next population. The value of $X_{i}^{(j, G+1)}$ is still obtained by equations (34)-(36).

4.4. Termination Criteria. In the optimization procedure, the search continues until the termination criterion is met [46]. The stopping criterion of this study is the maximal number of assigned iterations $G_{\max }$.
4.5. Optimization Procedure. The optimization procedure of a ship lock head was realized by a self-developed Python script that was imported into ABAQUS. An ABAQUS user subroutine (HETVAL) was developed using equation (23) to calculate the heat of hydration. Meanwhile, to calculate the thermal creep stress of concrete, an ABAQUS user subroutine (CREEP) was also developed accordingly using equations shown in Section 2.2.

4.5.1. GA. The optimization procedure is given as follows:

(1) A two-dimensional array was generated, which was the initial population of 34 design variables. The chromosomes represent the design variables.

(2) The binary digits of the initial population were decoded into decimal values of 34 design variables.

(3) Geometric and mesh models of a ship lock head were automatically established. The material properties, design loads, and boundary conditions were then automatically applied.

(4) The heat of hydration was calculated using equation (23). The temperature field was calculated using the equations shown in Section 2.1.

(5) Thermal creep stress was calculated using the solutions of the temperature field and the equations described in Section 2.2.

(6) The constraints defined in Section 3.4 were checked. If the result of the ship lock head satisfied all the constraints, the solution of the objective function value was determined using equation (26). Otherwise, the objective function was obtained using equation (27).

(7) Based on the initial population's objective function values, a new, better population was generated using the genetic operators shown in Section 4.1.4.

(8) The termination condition was checked. Steps 3-7 were repeated if the number of generations $G$ was not greater than the maximal number of assigned generations $G_{\max }$.

(9) The values of the 34 design variables with the highest objective function value obtained in Step 8 were output. They represented the optimal sizes of the ship lock head.

The flowchart summarizing all the steps is illustrated in Figure 7(a).

4.5.2. $H B B-B C$ and $B B-B C$. The optimization procedures of $\mathrm{HBB}-\mathrm{BC}$ and $\mathrm{BB}-\mathrm{BC}$ algorithms were similar. They are shown in Figure 7(b).

\section{Case Study}

5.1. Basic Information of Ship Lock Head. In this study, a ship lock head was presented, which was established on a rock foundation. It had a height of $12.3 \mathrm{~m}$ and a width of $53.8 \mathrm{~m}$. The ranges of 34 design variables are listed in Table 1. 


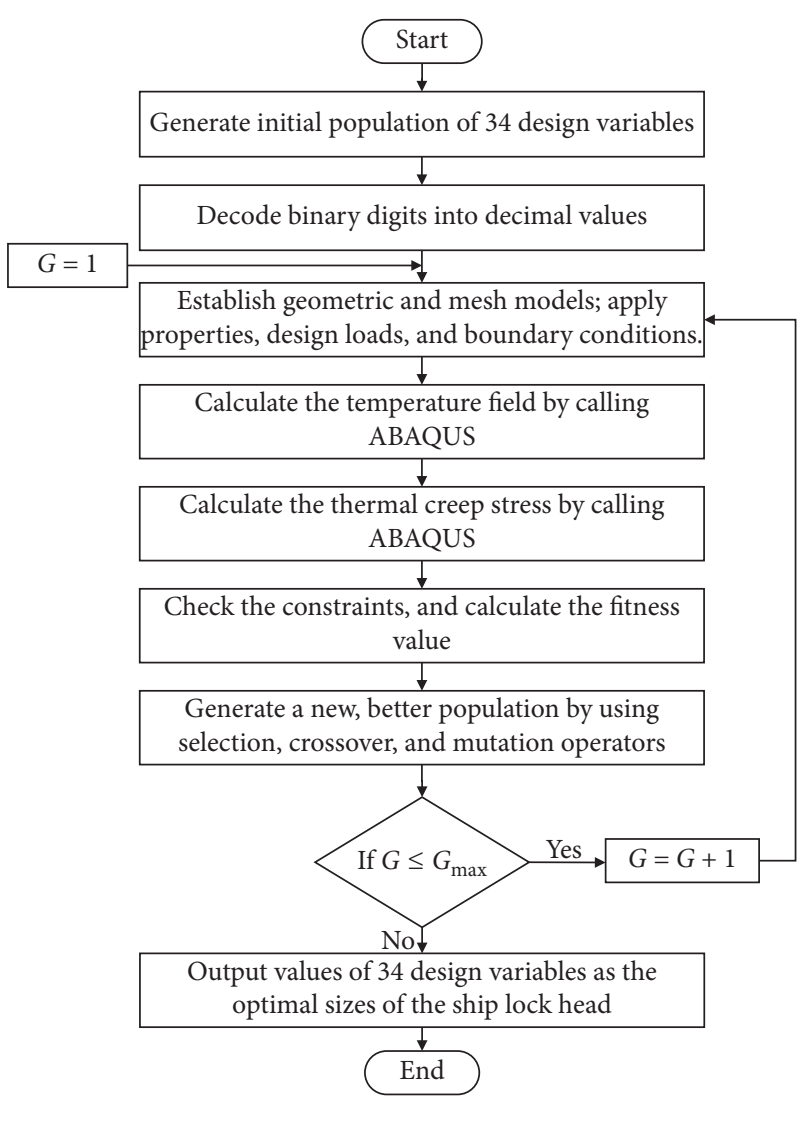

(a)

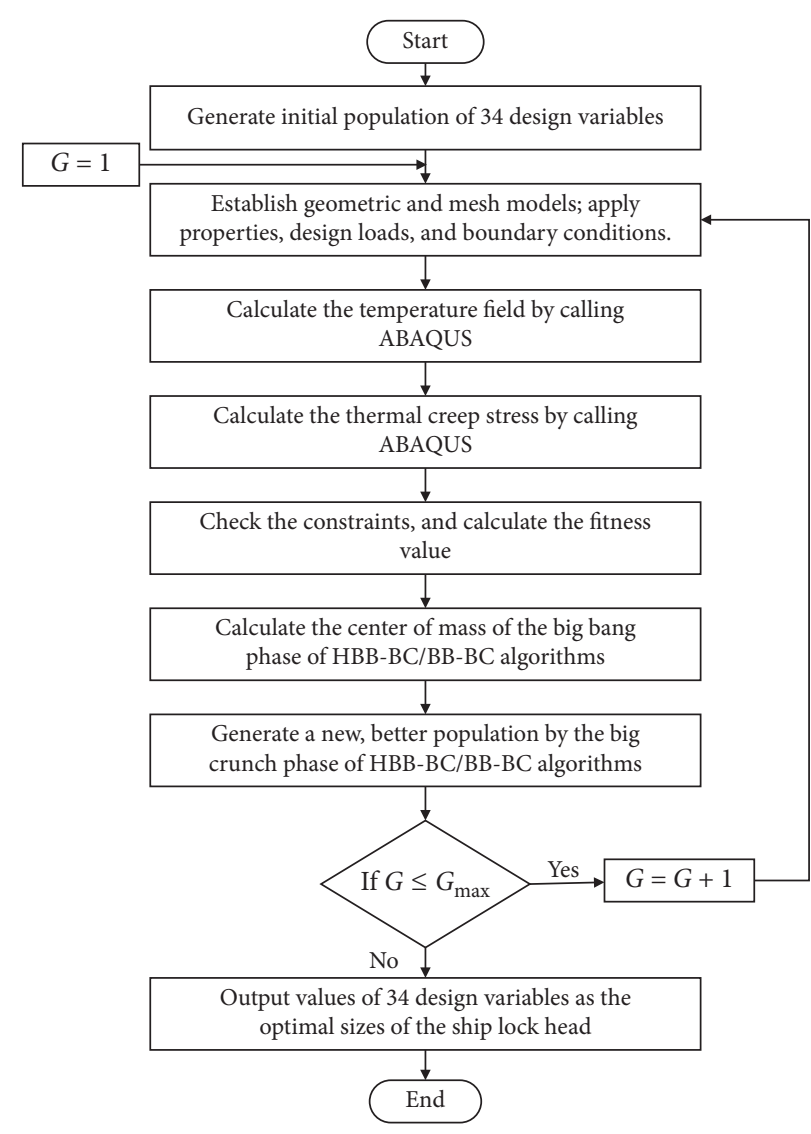

(b)

FIgUre 7: Flowcharts of the optimization of the ship lock head. (a) GA algorithm. (b) HBB-BC and BB-BC algorithms.

A creep model was adopted for this concrete structure. The elastic modulus of the concrete is as follows:

$$
E(\tau)=34.25\left[1-\exp \left(-0.28 \tau^{0.52}\right)\right] \times 10^{9} .
$$

The creep function is as follows:

$$
\begin{aligned}
C(t, \tau)= & \left\{6.39 \times\left(1+9.2 \tau^{-0.45}\right)[1-\exp (-0.3(t-\tau))]\right. \\
& \left.+14.5 \times\left(1+1.7 \tau^{-0.45}\right)[1-\exp (-0.005(t-\tau))]\right\} \\
& \times 10^{-12} .
\end{aligned}
$$

The other material properties of concrete are summarized in Table 2, and the properties of the bedrock and backfilled gravel are also listed in Table 2.

The total duration of the project was 369 days. As a longterm project, the detailed construction schedule is shown in Table 3. The initial temperature of the bedrock was $18.8^{\circ} \mathrm{C}$, which was the multiyear average value. Subsequently, the other initial temperatures of each section are also listed in Table 3.

For concrete, the heat of hydration can be obtained as follows:

$$
Q(\tau)=98167.48\left[1-\exp \left(-0.0033 \tau^{1.525}\right)\right]
$$

The air temperatures during the construction period were obtained using the following fit equation:

$$
T_{a}=17.92+8.15 \cos \left[\frac{\pi(\tau-110)}{180}\right] .
$$

The GA parameters used in this project were set as follows. The population size $g$ was 30 , and the chromosome length $p$ was 136. The maximum generation $G_{\max }$ was 25 . The crossover probability $p_{c}$ was 0.8 , and the mutation probability $p_{t}$ was 0.008 .

The HBB-BC and BB-BC parameters are shown as follows: $k_{j}$ represents a random number between $[-1,1]$, $n_{1}=1, n_{2}=0.4$, and $n_{3}=0.8$ [47].

5.2. Optimization Results. For this project, the optimization processes (as shown in Section 4.5) were completed using a workstation, which consisted of two fourteencore CPUs (Xeon E5-2680 v4, Intel Corporation). For 50 runs of the GA, BB-BC, and HBB-BC algorithms, the evolutionary optimization process of each algorithm's best design is presented in Figure 8. The optimization algorithms led to different results. The BB-BC and GA algorithms converged rapidly but fell into local optima. The HBB-BC algorithm produced the best design.

The optimal values of 34 design variables are presented in Table 1. Table 4 compares the ship lock head's initial volume and the optimum design obtained by each algorithm. The HBB-BC algorithm performed better in 
TABle 1: Design variables for the initial and optimum designs.

\begin{tabular}{|c|c|c|c|c|c|c|}
\hline \multirow{2}{*}{ Design variable number } & \multirow{2}{*}{ Direction } & \multirow{2}{*}{ Design variable } & \multicolumn{2}{|c|}{ Uniform distribution $(\mathrm{m})$} & \multirow{2}{*}{ Initial values $(\mathrm{m})$} & \multirow{2}{*}{ Optimum values (m) } \\
\hline & & & Minimum & Maximum & & \\
\hline 1 & $y$ & $y_{1}$ & 0.05 & 1.5 & 1.5 & 0.3 \\
\hline 2 & $y$ & $y_{2}$ & 0.05 & 0.3 & 0.3 & 0.05 \\
\hline 3 & $y$ & $y_{3}$ & 0.05 & 0.24 & 0.24 & 0.069 \\
\hline 4 & $y$ & $y_{4}$ & 0.44 & 1 & 1 & 0.573 \\
\hline 5 & $y$ & $y_{5}$ & 0.05 & 0.5 & 0.5 & 0.386 \\
\hline 6 & $y$ & $y_{6}$ & 0.05 & 0.3 & 0.3 & 0.178 \\
\hline 7 & $y$ & $y_{7}$ & 0.05 & 0.6 & 0.6 & 0.078 \\
\hline 8 & $x$ & $x_{1}$ & 0.05 & 0.7 & 0.7 & 0.623 \\
\hline 9 & $x$ & $x_{2}$ & 0.05 & 0.6 & 0.6 & 0.389 \\
\hline 10 & $x$ & $x_{3}$ & 0.5 & 0.9 & 0.9 & 0.504 \\
\hline 11 & $x$ & $x_{4}$ & 0.05 & 1.8 & 1.8 & 1.649 \\
\hline 12 & $x$ & $x_{5}$ & 0.1 & 1.14 & 0.6 & 0.333 \\
\hline 13 & $x$ & $x_{6}$ & 11.6 & 12 & 12 & 11.672 \\
\hline 14 & $x$ & $x_{7}$ & 0.05 & 1.5 & 1.5 & 0.615 \\
\hline 15 & $x$ & $x_{8}$ & 0.05 & 0.7 & 0.7 & 0.62 \\
\hline 16 & $x$ & $x_{9}$ & 0.05 & 0.6 & 0.6 & 0.45 \\
\hline 17 & $x$ & $x_{10}$ & 0.4 & 0.5 & 0.4 & 0.42 \\
\hline 18 & $x$ & $x_{11}$ & 0.05 & 0.7 & 0.7 & 0.6 \\
\hline 19 & $x$ & $x_{12}$ & 0.05 & 1.9 & 1.9 & 1.143 \\
\hline 20 & $z$ & $z_{1}$ & 3.3 & 4.58 & 4.58 & 4.3 \\
\hline 21 & $z$ & $z_{2}$ & 0.7 & 1.3 & 1.3 & 0.74 \\
\hline 22 & $z$ & $z_{3}$ & 0.05 & 0.23 & 0.23 & 0.101 \\
\hline 23 & $z$ & $z_{4}$ & 3.7 & 3.9 & 3.7 & 3.864 \\
\hline 24 & $z$ & $z_{5}$ & 0.05 & 0.7 & 0.7 & 0.5 \\
\hline 25 & $z$ & $z_{6}$ & 0.05 & 0.7 & 0.7 & 0.6 \\
\hline 26 & $z$ & $z_{7}$ & -1.3 & -0.5 & -0.5 & -0.721 \\
\hline 27 & $z$ & $z_{8}$ & 17.91 & 18.2 & 17.91 & 18.139 \\
\hline 28 & $z$ & $z_{9}$ & 0.166 & 0.2 & 0.166 & 0.2 \\
\hline 29 & $z$ & $z_{10}$ & 3.744 & 3.9 & 3.744 & 3.9 \\
\hline 30 & $z$ & $z_{11}$ & 3.8 & 4.0 & 3.8 & 3.88 \\
\hline 31 & $z$ & $z_{12}$ & 23 & 23.4 & 23 & 23.211 \\
\hline 32 & $z$ & $z_{13}$ & 0.05 & 0.7 & 0.7 & 0.7 \\
\hline 33 & $z$ & $z_{14}$ & 23.3 & 25.5 & 23.3 & 23.318 \\
\hline 34 & $z$ & $z_{15}$ & 0.05 & 0.4 & 0.4 & 0.37 \\
\hline
\end{tabular}

TABLE 2: Material properties anticipated for ship lock head construction.

\begin{tabular}{|c|c|c|c|c|}
\hline Definition & Symbol & Ship lock head & Bedrock & Backfilled gravel \\
\hline Mass density $\left(\mathrm{kg} / \mathrm{m}^{3}\right)$ & $\rho$ & 2400 & 2600 & 2000 \\
\hline Poisson's ratio & $\mu$ & 0.167 & 0.27 & 0.3 \\
\hline Elastic modulus $(\mathrm{Pa})$ & $E(\tau)$ & Equation (38) & 20 & 20 \\
\hline Linear expansion coefficient $\left(10^{-6} /{ }^{\circ} \mathrm{C}\right)$ & $\zeta$ & 7 & 7 & 7 \\
\hline Surface exothermic coefficient $\left(\mathrm{kJ} / \mathrm{m}^{2} \cdot \mathrm{h} \cdot{ }^{\circ} \mathrm{C}\right)$ (before dismantling formwork) & $\beta$ & 17.21 & 20.83 & 20.83 \\
\hline Surface exothermic coefficient $\left(\mathrm{kJ} / \mathrm{m}^{2} \cdot \mathrm{h} \cdot{ }^{\circ} \mathrm{C}\right)$ (after dismantling formwork) & $\beta$ & 56.67 & 20.83 & 20.83 \\
\hline Thermal conductivity coefficient $\left(\mathrm{kJ} / \mathrm{m} \cdot \mathrm{h} \cdot{ }^{\circ} \mathrm{C}\right)$ & $k$ & 8.34 & 10.467 & 10.699 \\
\hline Specific heat $\left(\mathrm{kJ} / \mathrm{kg} \cdot{ }^{\circ} \mathrm{C}\right)$ & $c$ & 0.984 & 0.708 & 0.745 \\
\hline
\end{tabular}

searching for the optimal solution. The structure volume was reduced by $9.4 \%$.

Figure 9 displays the effect of various population sizes $g$ on the HBB-BC algorithm's convergence history during 25 iterations. The population sizes were 20, 25, 30, 35, and 40 . When $g$ was 20 , the objective function value was stable at 0.908 after 17 iterations. Due to the small population sizes, the search failed to obtain the optimal solution. When the population size was 25 , the objective function value converged to the optimal solution of 0.9065 at the $18^{\text {th }}$ iteration. The convergence rate was faster than that when the population size was 30 . When the population sizes were 35 and 40 , the objective function values did not converge at the $25^{\text {th }}$ iteration. This confirmed that due to the large population size, the efficiency of convergence to the optimal solution was relatively low. This would result in a waste of 
TABLE 3: Ship lock head construction schedule and associated initial temperature.

\begin{tabular}{|c|c|c|c|c|}
\hline $\begin{array}{l}\text { Construction } \\
\text { sequence }\end{array}$ & Construction schedule & $\begin{array}{c}\text { Construction duration } \\
\text { (day) }\end{array}$ & $\begin{array}{c}\text { Construction } \\
\text { intermissions (day) }\end{array}$ & $\begin{array}{c}\text { Initial temperature } \\
\left({ }^{\circ} \mathrm{C}\right)\end{array}$ \\
\hline S1 & Pouring bottom plate & 1 & 7 & 15.13 \\
\hline S2 & Dismantling bottom plate's formwork & 1 & 33 & - \\
\hline S3 & Backfilling the first layer of gravel & 15 & 95 & 15 \\
\hline S4 & Pouring the corridor layer & 2 & 8 & 23.97 \\
\hline S5 & Dismantling corridor layer's formwork & 1 & 24 & - \\
\hline S6 & Backfilling the second layer of gravel & 17 & 23 & 15 \\
\hline S7 & Pouring the empty-box layer & 2 & 8 & 14.22 \\
\hline S8 & $\begin{array}{c}\text { Dismantling empty-box layer's } \\
\text { formwork }\end{array}$ & 1 & 54 & - \\
\hline S9 & Pouring the second-stage concrete & 1 & 7 & 9.78 \\
\hline S10 & $\begin{array}{l}\text { Dismantling the second-stage } \\
\text { concrete's formwork }\end{array}$ & 1 & 19 & - \\
\hline S11 & Backfilling the third layer of gravel & 20 & 29 & 15 \\
\hline
\end{tabular}

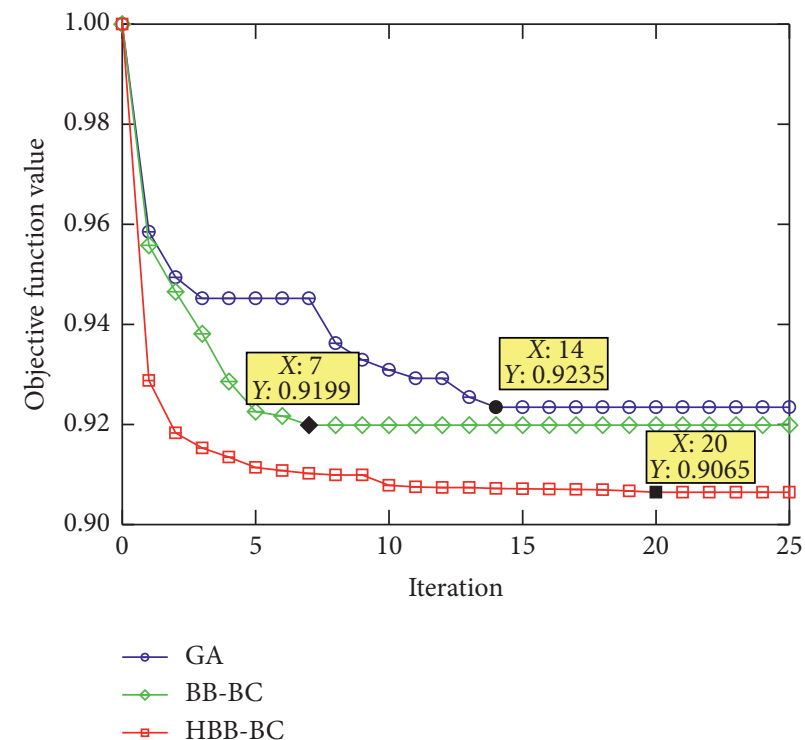

(a)

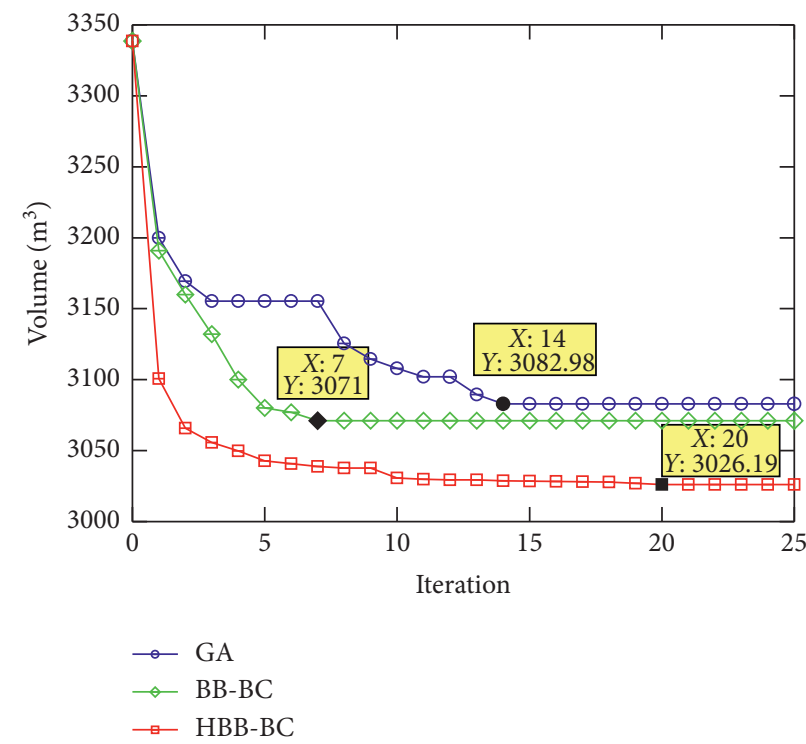

(b)

FIGURE 8: Evolutionary processes of GA, BB-BC, and HBB-BC algorithms. (a) Convergence of the objective function value. (b) Convergence of the concrete volume.

TABLE 4: Comparison for the initial and optimum designs.

\begin{tabular}{lccc}
\hline Volume $\left(\mathrm{m}^{3}\right)$ & GA & $\begin{array}{c}\text { BB-BC } \\
\text { algorithm }\end{array}$ & $\begin{array}{c}\text { HBB-BC } \\
\text { algorithm }\end{array}$ \\
\hline Initial design & 3338.5 & 3338.5 & 3338.5 \\
Optimal design & 3082.98 & 3071 & 3026.19 \\
Decreasing ratio (\%) & 7.7 & 8.0 & 9.4 \\
\hline
\end{tabular}

computational resources. The population size of 25 was more suitable for this study. The optimum volume of concrete was $3026.19 \mathrm{~m}^{3}$.

5.3. Analysis for Temperature Field of the Lock Head. Three feature points are identified in Figure 10, which were used to analyse the temperature and stress changes caused by structural optimization during the construction period. To intuitively understand each construction step's influence, the three points were located at lateral walls of the bottom plate, corridor, and empty-box layers.

Figure 11(a) shows the temperature changes of selected points during the construction period. The temperature increased rapidly when pouring the corridor and empty-box layers. The subsequent temperature changes almost corresponded to the change in the air temperature. The temperature rise reached $18^{\circ} \mathrm{C}$, while the temperature rise was approximately $10.5^{\circ} \mathrm{C}$ when pouring the bottom plate. This result suggests that the implementation of temperature control measures should give priority to the thin-walled sections during construction.

Compared with the initial design, Figure 11(b) shows that the bottom plate's temperature field was virtually unaffected by the size changes of the empty-box layer and the 


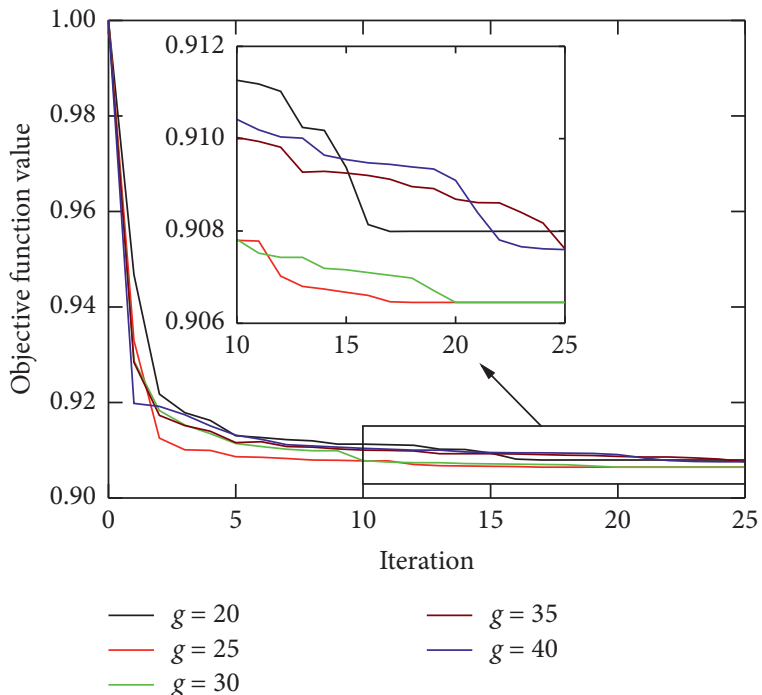

(a)

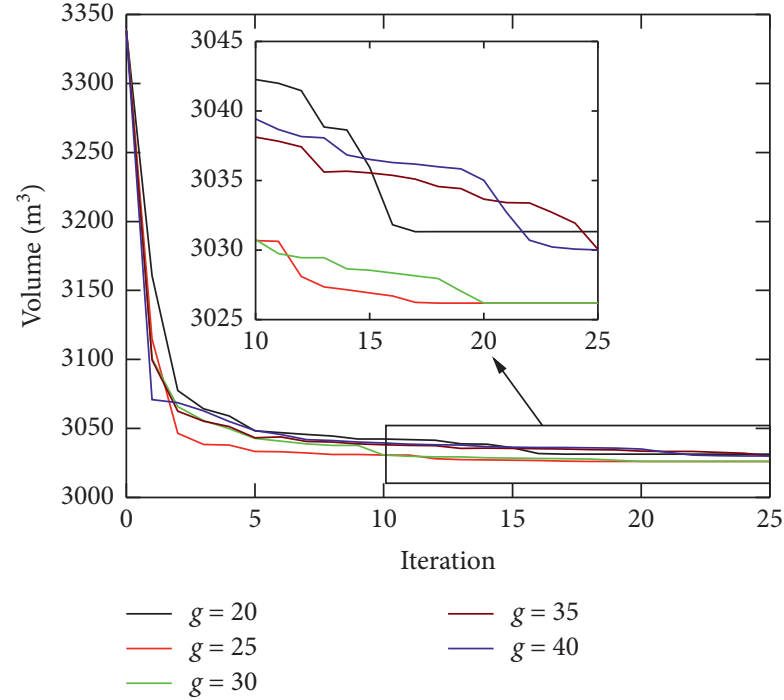

(b)

FIGURE 9: Effect of population size $g$ on the HBB-BC algorithm's convergence history. (a) Convergence of the objective function value. (b) Convergence of the concrete volume.

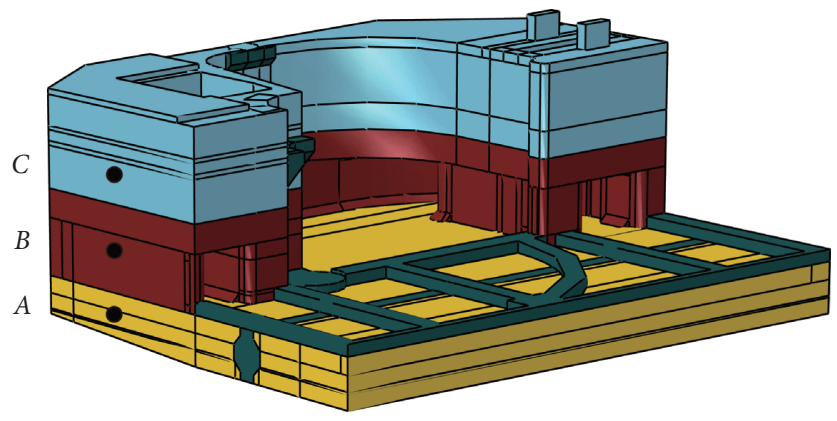

FIgURE 10: Locations of three feature points.

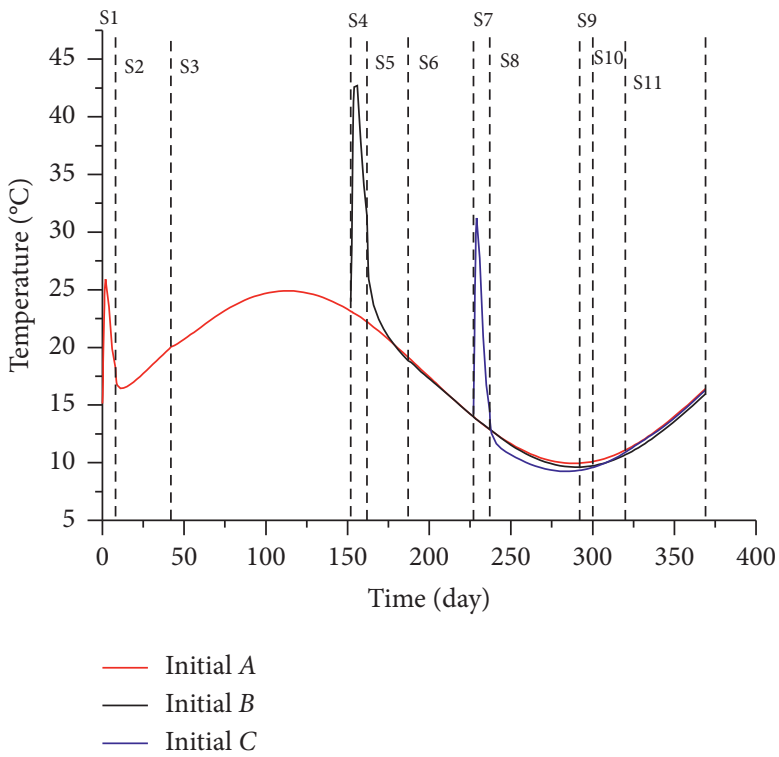

(a)

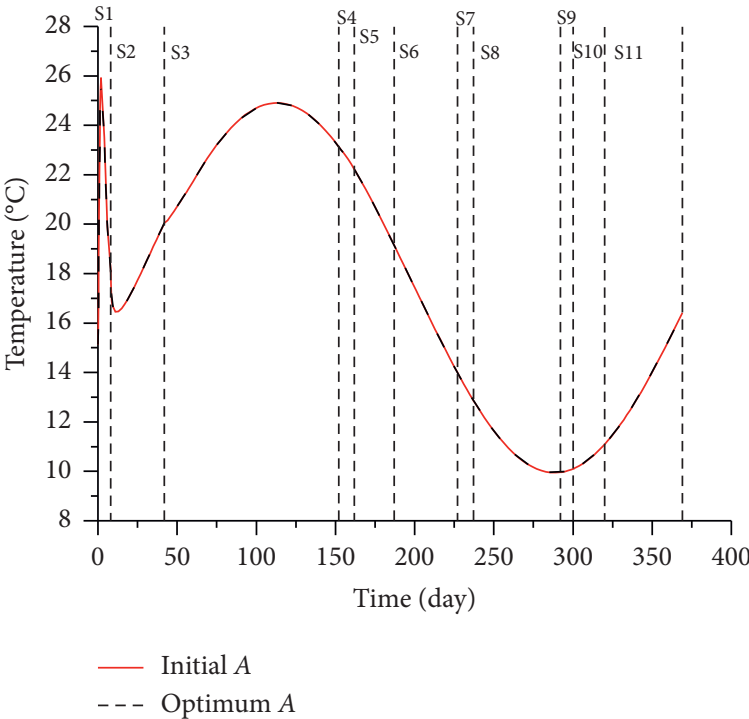

(b)

FIGURE 11: Continued. 


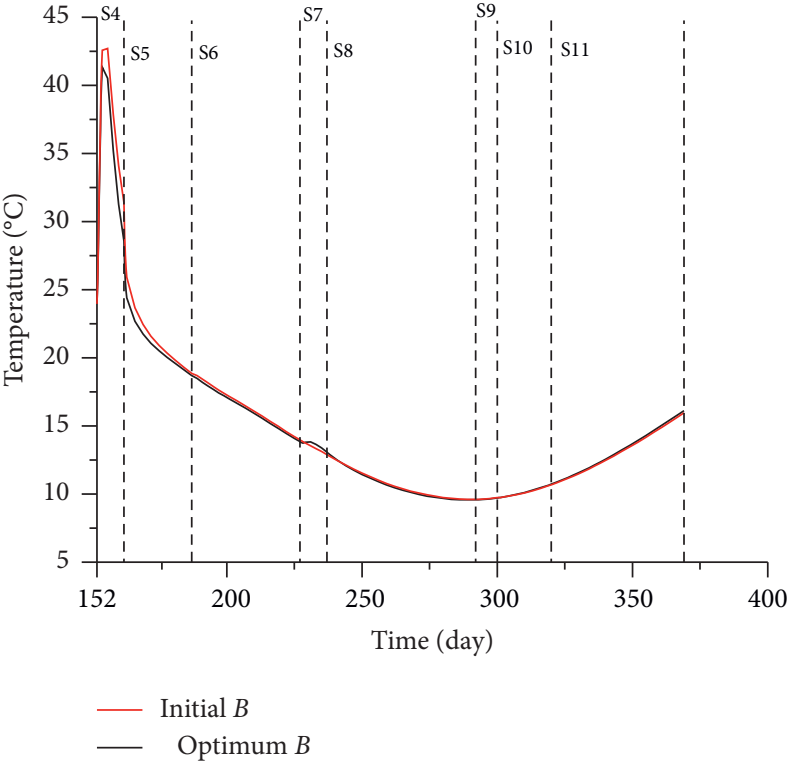

(c)

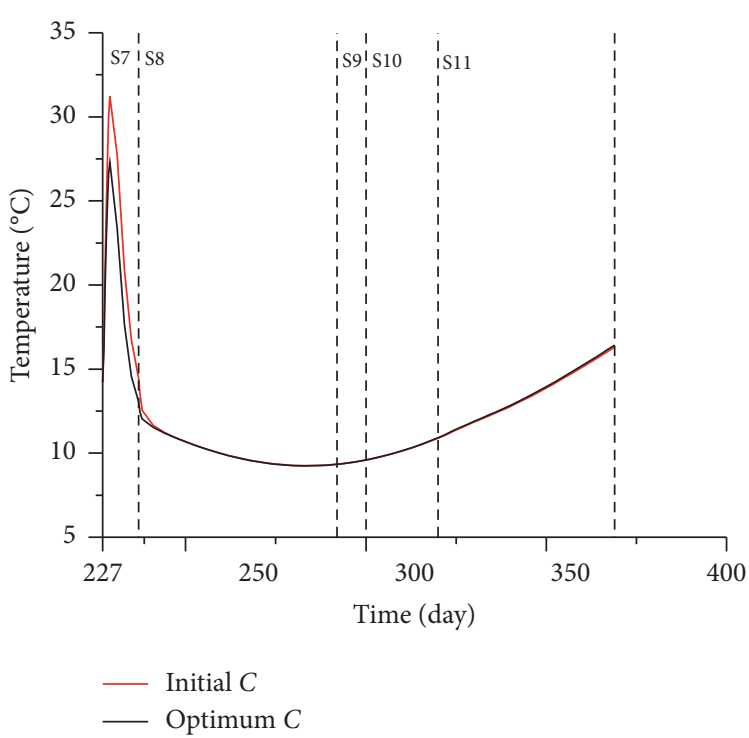

(d)

FIGURE 11: Time-course curves for temperature histories of three feature points. (a) Initial design. Before and after optimization at (b) point $A$, (c) point $B$, and (d) point $C$.

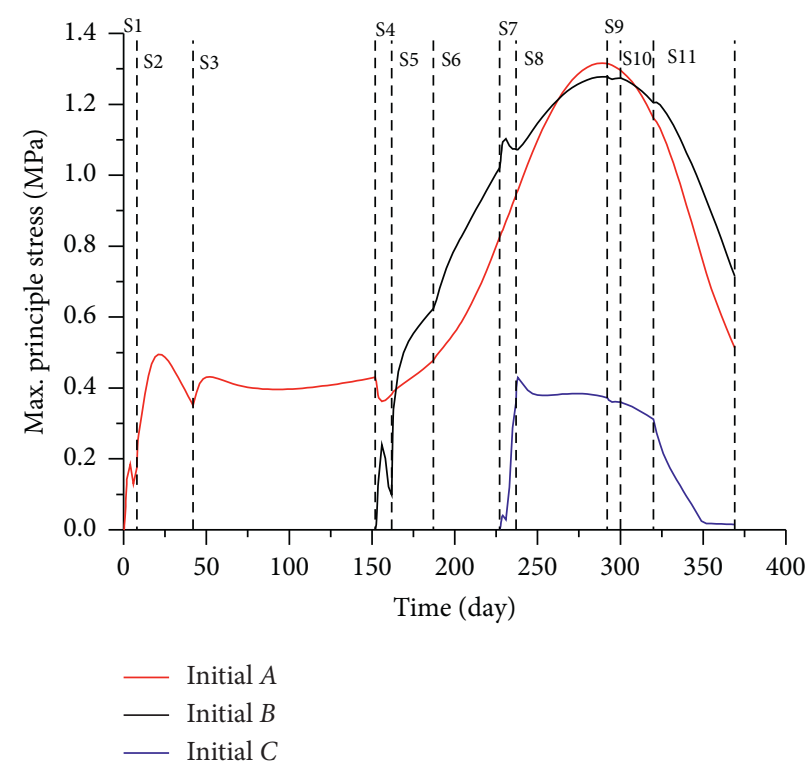

(a)

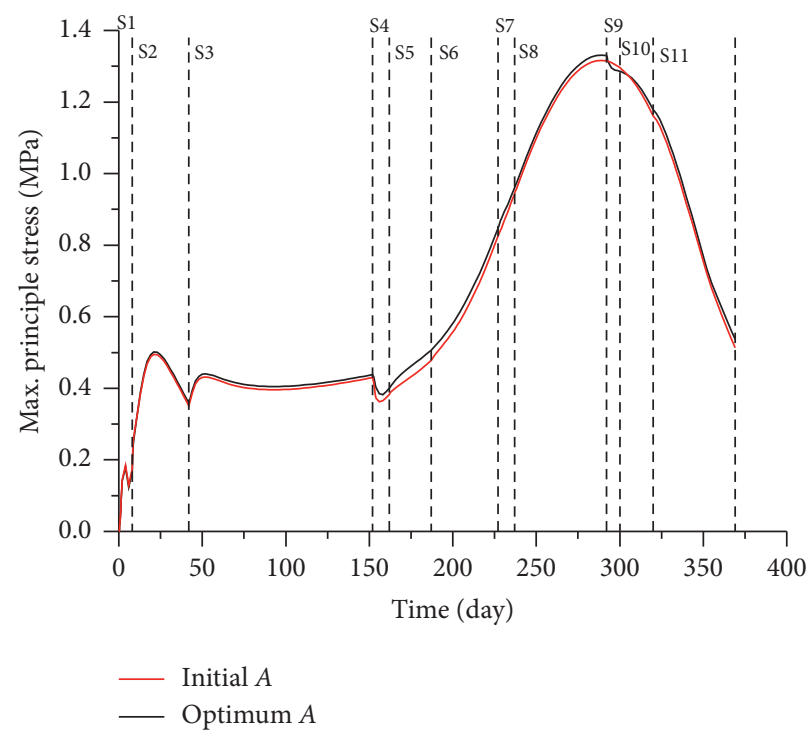

(b)

Figure 12: Continued. 


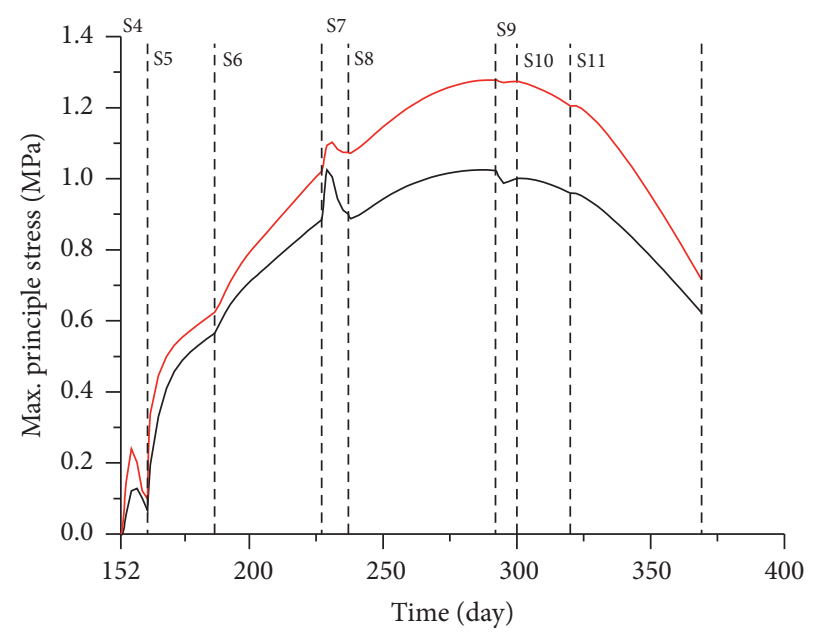

Initial $B$
Optimum $B$

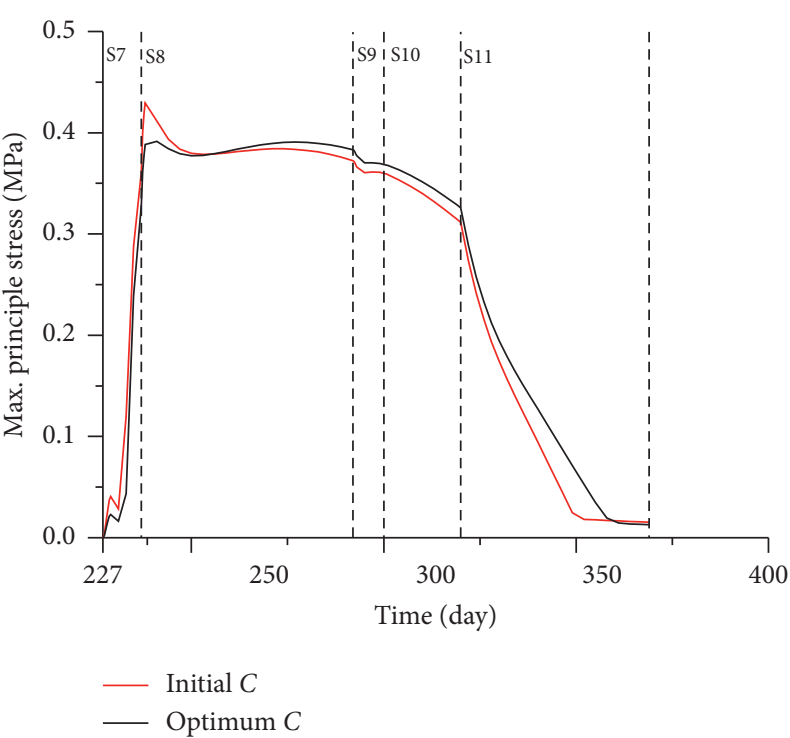

(d)

Figure 12: Time-course curves for the maximum (max.) principle stresses of three feature points. (a) Initial design. Before and after optimization at (b) point $A$, (c) point $B$, and (d) point $C$.

corridor layer. As shown in Figure 11(c), at the corridor layer, the optimum structure's maximum temperature decreased by $2.5^{\circ} \mathrm{C}$. The thinning of the lateral walls would increase the rate of heat dissipation. Figure 11(d) shows that structural optimization significantly affected the empty-box layer. The maximum temperature of the empty-box layer decreased by $4.3^{\circ} \mathrm{C}$. Thus, the structural optimization helped to reduce the temperature rise when pouring the concrete.

5.4. Analysis for Stress Field of Lock Head. Figure 12(a) shows the calculated maximum principle stresses of selected points during the construction period. The tensile stress was small after taking creep behaviour into account when pouring the concrete. The tensile stress then increased to the maximum value with the increase in the concrete elastic modulus. Thus, the stress field of the ship lock head was mainly affected by the thermal stress. The creep model could reflect the actual stress field. The tensile stresses of the bottom plate and the corridor layer reached 1.2 $\mathrm{MPa}$, which was much larger than the value with only the empty-box layer. Comparing Figures 11(a) and 12(a), the tensile stress developed to a maximum value when the temperature dropped to the minimum value. It was concluded that temperature control measures should be applied during winter to avoid thermal cracks.

As shown in Figure 12(b), compared with the initial design, the bottom plate's tensile stress increased by $0.03 \mathrm{MPa}$ due to the reduced volume of the corridor and the empty-box layers. Figure 12(c) shows that the optimum design reduced the corridor layer's tensile stress during the construction period. The maximum value could be reduced by $0.28 \mathrm{MPa}$. Figure $12(\mathrm{~d})$ shows that the optimum design decreased the corridor layer's tensile stress when pouring the concrete. Due to the reduction of the structure self-weight, the tensile stress was subsequently larger than that of the initial design with the increase in the concrete elastic modulus. For the emptybox layer, the maximum values could be increased by $0.07 \mathrm{MPa}$. In general, structural optimization helped to decrease the tensile stress significantly when pouring concrete. However, for the bottom plate and the emptybox layer, the reduction of the structure's self-weight will have some increasing effect on the tensile stress in the subsequent construction period.

\section{Conclusions}

In this study, the structural optimization of a ship lock head during the construction period was considered. Three optimization procedures based on the GA, BB-BC, and HBB-BC algorithms were developed. The optimization process aimed to determine the minimum volume of concrete. Thirty-four design variables of the corridor layer and the empty-box layer were chosen as updating parameters in the optimization processes. Based on the calculation results of the case study, the HBB-BC algorithms could obtain a better solution. The procedure comprised the calculation of the concrete temperature and stress fields, considering the time-varying properties of concrete. A set of implicit recursive equations proposed by Zhu were adopted to calculate the thermal creep stress. The storage of the stress history could be avoided, thereby reducing the memory consumption during the calculation process.

Through the analysis of the temperature and stress fields of the lock head, the following important conclusions are summarized: 
(1) The temperature increased rapidly in the thin-walled sections (such as the corridor and empty-box layers) when pouring the concrete.

(2) Structural optimization helped to reduce the temperature rise when pouring the concrete, especially in the empty-box layer.

(3) The stress field of the ship lock head was mainly affected by thermal stress. The tensile stress of the lock head was low at early ages. It subsequently increased with the improvement of the elastic modulus. The tensile stresses of the bottom plate and the corridor layer were at high levels in the winter. The linear viscoelastic creep model could reflect the actual stress field's variation rule of the ship lock head during the construction period.

(4) Structural optimization helped to decrease the tensile stress previously when pouring concrete. In particular, at the corridor layer, it was around a 50\% decrease. The reduction of the structure's self-weight had an increasing effect on the tensile stress in the subsequent construction period for the bottom plate and the empty-box layer.

Based on these four conclusions, it is appropriate to introduce creep behaviour into structural optimization during the construction period. Future work should consider solar radiation in the calculation of the mass concrete structure's temperature field.

\section{Data Availability}

The data used to support the findings of this study are included within the article.

\section{Conflicts of Interest}

The authors declare that there are no conflicts of interest regarding the publication of this paper.

\section{Acknowledgments}

This work was supported by the National Natural Science Foundation of China (no. 51579089).

\section{References}

[1] V. Bugarski, T. Bačkalić, and U. Kuzmanov, "Fuzzy decision support system for ship lock control," Expert Systems with Applications, vol. 40, no. 10, pp. 3953-3960, 2013.

[2] C. Su, N. Jiang, and J. Wang, "Optimization design of chamfer triangular gate lock structure," Port \& Waterway Engineering (Chinese Journal), vol. 479, no. 5, pp. 124-129, 2013.

[3] H. Zhou, Y. Zhou, C. Zhao, F. Wang, and Z. Liang, "Feedback design of temperature control measures for concrete dams based on real-time temperature monitoring and construction process simulation," KSCE Journal of Civil Engineering, vol. 22, no. 5, pp. 1584-1592, 2018.

[4] R. Luna and Y. Wu, "Simulation of temperature and stress fields during RCC dam construction," Journal of Construction Engineering and Management, vol. 126, no. 5, pp. 381-388, 2000.
[5] M. Ishikawa, "Thermal stress analysis of a concrete dam," Computers \& Structures, vol. 40, no. 2, pp. 347-352, 1991.

[6] X. Liu, C. Zhang, X. Chang, W. Zhou, Y. Cheng, and Y. Duan, "Precise simulation analysis of the thermal field in mass concrete with a pipe water cooling system," Applied Thermal Engineering, vol. 78, pp. 449-459, 2015.

[7] C. Xu and C. Su, "Development of an effective method for calculations related to creep," Arabian Journal for Science and Engineering, vol. 43, no. 4, pp. 1561-1571, 2018.

[8] R. Belevičius, D. Jatulis, and D. Šešok, "Optimization of tall guyed masts using genetic algorithms," Engineering Structures, vol. 56, pp. 239-245, 2013.

[9] G. Qin, J. Li, N. Jiang et al., "Warehouse optimization model based on genetic algorithm," Mathematical Problems in Engineering, vol. 2013, Article ID 619029, 6 pages, 2013.

[10] A. Salemi, R. Mikaeil, and S. S. Haghshenas, "Integration of finite difference method and genetic algorithm to seismic analysis of circular shallow tunnels (case study: tabriz urban railway tunnels)," KSCE Journal of Civil Engineering, vol. 22, no. 5, pp. 1978-1990, 2018.

[11] S.-W. Park, H. M. Park, and J.-J. Hwang, "Application of genetic algorithm and finite element method for back calculating layer moduli of flexible pavements," KSCE Journal of Civil Engineering, vol. 14, no. 2, pp. 183-190, 2010.

[12] Q. Cai, J. Sheng, and Z. Li, “An advanced genetic algorithm applied to a rare uplifting earth and rockfill dam," KSCE Journal of Civil Engineering, vol. 22, no. 12, pp. 4862-4871, 2018.

[13] P. Nanakorn and K. Meesomklin, "An adaptive penalty function in genetic algorithms for structural design optimization," Computers \& Structures, vol. 79, no. 29-30, pp. 2527-2539, 2001.

[14] O. K. Erol and I. Eksin, "A new optimization method: big Bang-Big Crunch," Advances in Engineering Software, vol. 37, no. 2, pp. 106-111, 2006.

[15] M. Sedighizadeh, M. Esmaili, and A. Eisapour-Moarref, "Voltage and frequency regulation in autonomous microgrids using hybrid Big Bang-Big Crunch algorithm," Applied Soft Computing, vol. 52, pp. 176-189, 2017.

[16] Z. Tabrizian, E. Afshari, G. G. Amiri, M. H. Ali Beigy, and S. M. P. Nejad, "A new damage detection method: Big BangBig Crunch (BB-BC) algorithm," Shock and Vibration, vol. 20, no. 4, pp. 633-648, 2013.

[17] A. Kaveh and S. Talatahari, "Size optimization of space trusses using Big Bang-Big Crunch algorithm," Computers \& Structures, vol. 87, no. 17-18, pp. 1129-1140, 2009.

[18] C. V. Camp and F. Huq, " $\mathrm{CO}_{2}$ and cost optimization of reinforced concrete frames using a big bang-big crunch algorithm," Engineering Structures, vol. 48, pp. 363-372, 2013.

[19] M. Rita, E. Fairbairn, F. Ribeiro et al., "Optimization of mass concrete construction using a twofold parallel genetic algorithm," Applied Sciences, vol. 8, no. 3, pp. 1-18, 2018.

[20] E. M. R. Fairbairn, M. M. Silvoso, R. D. Toledo Filho, J. L. D. Alves, and N. F. F. Ebecken, "Optimization of mass concrete construction using genetic algorithms," Computers \& Structures, vol. 82, no. 2-3, pp. 281-299, 2004.

[21] K. A. Riding, J. L. Poole, A. K. Schindler et al., "Evaluation of temperature prediction methods for mass concrete members," ACI Materials Journal, vol. 103, no. 5, pp. 357-365, 2006.

[22] E. L. Wilson and R. E. Nickell, "Application of the finite element method to heat conduction analysis," Nuclear Engineering and Design, vol. 4, no. 3, pp. 276-286, 1966.

[23] E. L. Wilson, K. J. Bathe, and F. E. Peterson, "Finite element analysis of linear and nonlinear heat transfer," Nuclear Engineering and Design, vol. 29, no. 1, pp. 110-124, 1974. 
[24] A. I. H. Malkawi, S. A. Mutasher, and T. J. Qiu, “Thermalstructural modeling and temperature control of roller compacted concrete gravity dam," Journal of Performance of Constructed Facilities, vol. 17, no. 4, pp. 177-187, 2003.

[25] K. Yang, Y. Ding, P. Sun et al., "Modeling of temperature time-lag effect for concrete box-girder bridges," Applied Sciences, vol. 9, no. 16, pp. 1-15, 2019.

[26] E. Castilho, N. Schclar, C. Tiago, and M. L. B. Farinha, "FEA model for the simulation of the hydration process and temperature evolution during the concreting of an arch dam," Engineering Structures, vol. 174, pp. 165-177, 2018.

[27] Y. Zhou, D. Meng, and Y. Wang, "Finite-element simulation of hydration and creep of early-age concrete materials," Journal of Materials in Civil Engineering, vol. 26, no. 11, Article ID 05014006, 2014.

[28] K. A. James and H. Waisman, "Topology optimization of viscoelastic structures using a time-dependent adjoint method," Computer Methods in Applied Mechanics and Engineering, vol. 285, pp. 166-187, 2015.

[29] Z. P. Bažant, Q. Yu, and G. H. Li, "Excessive long-time deflections of prestressed box girders. II: numerical analysis and lessons learned," Journal of Structural Engineering, vol. 138, no. 6, pp. 687-696, 2012.

[30] G. Zi and Z. P. Bažant, "Continuous relaxation spectrum for concrete creep and its incorporation into microplane model M4," Journal of Engineering Mechanics, vol. 128, no. 12, pp. 1331-1336, 2002.

[31] ACI Committe 209, Guide for Modeling and Calculating Shrinkage and Creep in Hardened Concrete, American Concrete Institute, Farmington Hills, MI, USA, ACI209.2R-08, 2008.

[32] Z. P. Bažant and Y. Xi, "Continuous retardation spectrum for solidification theory of concrete creep," Journal of Engineering Mechanics, vol. 121, no. 2, pp. 281-288, 1995.

[33] J. H. Hattel and J. Thorborg, "A numerical model for predicting the thermomechanical conditions during hydration of early-age concrete," Applied Mathematical Modelling, vol. 27, no. 1, pp. 1-26, 2003.

[34] B. Zhu, Thermal Stresses and Temperature Control of Mass Concrete, Butterworth-Heinemann, Amsterdam, Netherlands, 2013.

[35] M. Zyczkowski, "Optimal structural design under creep conditions," Applied Mechanics Reviews, vol. 41, no. 12, pp. 453-461, 1988.

[36] Q. B. Li, G. H. Liang, Y. Hu et al., "Numerical analysis on temperature rise of a concrete arch dam after sealing based on measured data," Mathematical Problems in Engineering, vol. 2014, Article ID 602818, 12 pages, 2014.

[37] H. Su, J. Li, and Z. Wen, "Evaluation of various temperature control schemes for crack prevention in RCC arch dams during construction," Arabian Journal for Science and Engineering, vol. 39, no. 5, pp. 3559-3569, 2014.

[38] M. S. Jaafar, K. H. Bayagoob, J. Noorzaei et al., "Development of finite element computer code for thermal analysis of roller compacted concrete dams," Advances in Engineering Software, vol. 38, no. 11-12, pp. 886-895, 2007.

[39] L. J. Sergerlind, Applied Finite Element Analysis, John Wiley \& Sons, New York, NY, USA, 1984.

[40] Y. Y. Huang, H. Zheng, and Y. H. Zhou, "Study of thermal stress for mass concrete considering concrete age and elasticplasticity creep," Journal of Sichuan University (Engineering Science Edition), vol. 43, no. 2, pp. 22-27, 2011.

[41] JTJ 307-2001, Code for Design of Hydraulic Structures of Ship Locks, Chinese Standard, Beijing, China, 2001.
[42] Y. Xu, M. Zeng, Q. Liu et al., "A genetic algorithm based multilevel association rules mining for big datasets," Mathematical Problems in Engineering, vol. 2014, Article ID 867149, 9 pages, 2014.

[43] F. Zhao, Z. Yao, J. Luan et al., "A novel fused optimization algorithm of genetic algorithm and ant colony optimization," Mathematical Problems in Engineering, vol. 2016, Article ID 2167413, 10 pages, 2016.

[44] C. V. Camp, "Design of space trusses using big bang-big crunch optimization," Journal of Structural Engineering, vol. 133, no. 7, pp. 999-1008, 2007.

[45] M. Sedighizadeh and R. Bakhtiary, "Optimal multi-objective reconfiguration and capacitor placement of distribution systems with the hybrid Big Bang-Big Crunch algorithm in the Fuzzy framework," Ain Shams Engineering Journal, vol. 7, no. 1, pp. 113-129, 2016.

[46] A. P. Giddings, R. L. Rardin, and R. Uzsoy, "Statistical optimum estimation techniques for combinatorial optimization problems: a review and critique," Journal of Heuristics, vol. 20, no. 3, pp. 329-358, 2014.

[47] A. Kaveh and S. Talatahari, "Optimal design of Schwedler and ribbed domes via hybrid Big Bang-Big Crunch algorithm," Journal of Constructional Steel Research, vol. 66, no. 3, pp. 412-419, 2010. 